\title{
La producción fotográfica escolar de Ezequiel Fernández Santana 100 años después (1915-2015) ${ }^{1}$
}

\author{
The school photography production of Ezequiel Fernández Santana 100 \\ years later (1915-2015)
}

A produção fotográfica escolar de Ezequiel Fernández Santana 100 anos depois (1915-2015)

\author{
José Soto Vázquez ${ }^{2}$ \\ Ramón Pérez Parejo ${ }^{3}$ \\ Universidad de Extremadura, Cáceres (España)
}

Recepción: 20/01/2016

Evaluación: 19/04/2016

Aceptación: 24/08/2017

Artículo de Investigación - Reflexión

DOI: https://doi.org/10.19053/01227238.7579

\section{RESUMEN}

Recientes estudios han demostrado las España. Los cristales originales fueron interesantes aportaciones de la fotografía escolar al ámbito de la investigación en Historia de la Educación. En este contexto, las fotografías de Ezequiel Fernández Santana, tomadas entre 1915 y 1938, constituyen un hito en la historia de la fotografía escolar de hallados en un vertedero, después fueron restaurados y digitalizados, según los criterios contemporáneos para fondos documentales, así como catalogados para su correcta identificación, cronología, y tema. Su conservación actual permitirá el estudio de la fotografía escolar con fines

$1 \quad$ El presente artículo se enmarca en la actividades del Proyecto de Iniciación a la Investigación "La recuperación y análisis de patrimonio fotográfico de las Escuelas del Ave María en Extremadura: Ezequiel Fernández Santana" de la Universidad de Extremadura (2011-2013), del que es investigador responsable José Soto Vázquez. Número de expediente: UNEX-ACCVII. Exp. 2032. Este artículo se incluye en las actividades realizadas por el Grupo de Investigación "LIJ" del Catálogo de grupos de la Junta de Extremadura (SEJ036), Coordinado por José Soto Vázquez. Ayudas cofinanciadas por FONDOS FEDER. Programa Operativo FEDER de Extremadura 2014-2020. № de Expediente GR15006.

2 (Los Santos de Maimona, Badajoz, España) es Doctor en Filología Hispánica por la Universidad de Extremadura. Es profesor del Departamento de Didáctica de las Ciencias Sociales, de las Lenguas y de las Literaturas en la Universidad de Extremadura (Cáceres). Codirige la revista Tejuelo. Didáctica de la Lengua y la Literatura. Educación.

3 (Santa Amalia, Badajoz, España) es Doctor en Filología Hispánica por la Universidad de Extremadura y Master de Enseñanza de Español para Extranjeros por la Universidad Antonio de Nebrija de Madrid. Ejerce de profesor de Didáctica de la Lengua en la Universidad de Extremadura. Codirige la revista Tejuelo. Didáctica de la Lengua y la Literatura. Educación.. Email: (rpp@unex.es). 
artísticos y propagandísticos, dado que estos materiales constituyen un ejemplo único en este sentido. El corpus supone un material inédito y exclusivo, no solo por proceder de un mismo fotógrafo, sino también por su cantidad (220 imágenes), su unidad temática, y su perspectiva pedagógica. De este modo se aúna en su figura el valor de la fotografía tomada in media res por el mismo maestro.

Palabras clave: Revista Historia de la Educación; arte; enseñanza y formación; escuela; fotografía.

\section{ABSTRACT}

Recent studies have revealed the interesting contributions of school photography to the research field History of Education. In this context, the photographs produced by Ezequiel Fernández Santana, taken between 1915 and 1938, constitute a milestone in the history of school photography in Spain. The original crystals were found in a landfill, so the had to be restored and digitized, according to contemporary criteria for documentary collections, as well as cataloged for their correct identification, chronology, and theme. Its current conservation will allow the study of school photography for artistic and propagandistic purposes, given that these materials account for a unique example in this regard. The corpus is an unpublished and exclusive material, not only because it comes from the same photographer, but also because of the amount (220 images), the conceptual unit, and the pedagogical perspective. In this sense, we have a work of double value, since the photographs were taken in media res by the teacher himself.

Keywords: Journal History of Latin American Education; art; education and training; school; photography.

\section{RESUMO}

Recentes estudos demonstraram as interessantes contribuições da fotografia escolar no âmbito da pesquisa em História da Educação. Nesse contexto, as fotografias de Ezequiel Fernández Santana, produzidas entre 1915 e 1938, constituem um marco na história da fotografia escolar da Espanha. As lentes originais foram encontradas em um aterro sanitário, e depois foram restauradas e digitalizadas, segundo os critérios contemporâneos para fundos documentais, assim como catalogados para sua correta identificação, cronologia e tema. Sua conservação atual permitirá o estudo da fotografia escolar com fins artísticos e propagandísticos, dado que estes materiais constituem um exemplo único neste sentido. $\mathrm{O}$ corpus supõe um material inédito e exclusivo, não somente por proceder de um mesmo fotógrafo, senão também por sua quantidade (220 imagens), sua unidade temática e sua perspectiva pedagógica. Deste modo se reúne em sua figura o valor da fotografia tomada in media res pelo mesmo professor.

Palavras-chave: Revista História da Educação; arte; ensino e formação; escola; fotografia.

Contextualización: Idioma Maya Mam

Contextualizador: Rosendo Ordóñez Maldonado

Ministerio de Educación de Guatemala

\section{CH'IN TUMILAL}

Matz'el nikyb'aj ti'j tb'inchb'en tib'lal jaku onin nimxix ti'j xpich'b'il ti'j tza'n matzaj b'et xnaq'tzb'il teitz tx'otx' kyxol, xjal. Atzun txilen qe tib'lal machib'ant tu'n Ezequiel Fernández Santana tuj t-ab' q'iyil 1915 ex 1938, ntq'ama'n txilen titz'jleni qe tib'lal toj xnaq'tzb'il twitz kytx'otx' kyxe'cil amq' jlajxi nim a'. Nti'taq okq'0'n kyipumal tej kykanet tnejil kyu'n xjal toj jun tenb'il nyaxix tb'anil, oktzun jun aq'untl ti'j tun tb'aj b'inchet ex tu'n tkoletqe kyjatzun okq'o'n xpich'b'il ti'j 
jatumil itzaj kanet ex ti' nkyq'ama'n tuj ju'jun anb'il tej kyb'inchet. Atzun jun kyb'an ja'lu tu'n tb'aj q'amet ex tu'n txiyek'at tonb'il ti'j ju'njun xnaq'tzb'il ex tza'n tu'n tajb'en qu'n tuj tumilalxix. Kyaqiltzun b'ib'il aju nti' lo'maj kyu'n xjal, b'ele tu'ntlaj taq'anb'en junx xjal y nimxix tajlal tu'n tb'aj nuk'b'et, ti'j xnaq'tzb'il ex tu'n tel qniky' ti' ntaq'a'n ju'jun tib'lal. Kyjatzun a jun tumilal nkyq'ama'n tib'lal twitz qnab'il ntzaj qe' tmij jun tanq'ib'il xjal Tipumal yol: Ujb'il q'ol tnab'il xnaq'tzb'il; b'inchab'il; yek'b'il ex xnaq'tzb'il; jaxnaq'tz, tib'lal

En 2015 se celebra el centenario del inicio de la labor fotográfico-escolar de Ezequiel Fernández Santana (1874-1938), lo que representa un hito poco conocido en la historia de la fotografía escolar en España. El presente estudio constituye la culminación de una serie de investigaciones previas realizadas al amparo del proyecto "La recuperación y análisis de patrimonio fotográfico de las Escuelas del Ave María en Extremadura” durante los últimos cuatro años con el que se pretende dar a conocer este valioso material fotográfico, su debida catalogación, así como el contexto pedagógico en que tuvo lugar.

\section{INTRODUCCIÓN}

Es innegable el aumento de los estudios sobre fotografía escolar como medio de conocimiento de la realidad escolar española a través de la historia contemporánea. Significativas son, en este sentido, las aportaciones de Sanchidrián Blanco ${ }^{4}$, quien entiende la gran aportación que, a la denominada cultura visual que impera hoy día, supone la incorporación de las fuentes fotográficas al estudio de la Historia de la Educación, desdeñada en otros tiempos por su falta de credibilidad y verismo, si bien conviene añadir que no se puede estudiar la imagen fotográfica lejos de las modas y usos contemporáneos de la sociedad en la que nacen ${ }^{5}$.

Desde esta óptica, el recorrido ha sido breve, aunque muy significativo. En este sentido las primeras aportaciones surgen del congreso de la ISCHE celebrado en 1998 en Lovaina bajo el tema: El papel de lo visual en la construcción del espacio educativo a través de la historia de la educación, cuyas reflexiones se editaron como The History of Education and the Challenge of the Visual ${ }^{6}$. A este hito seguirán las reflexiones de la European Educational Research Association (2001) y un largo etcétera, que como bien resume Sanchidrián Blanco ${ }^{7}$, se han centrado en los siguientes aspectos:

Las imágenes se han usado sobre todo en cuatro grandes campos:

1. Estudio de relaciones de género en las aulas.

2. Análisis de la cultura material de la educación (no solo de la escuela).

3. Temas relacionados con infancia, marginación y educación social.

4 C. Sanchidrián Blanco, "El uso de imágenes en la investigación histórico-educativa", Revista de Investigación Educativa 29, No. 2 (2011): 295-309.

5 J. Baeza, Por una función crítica de la fotografía de prensa (Barcelona: Gustavo Gili, 2001), 160 y ss.

6 M. Depaepe y B. Henkens (Eds.). Imagine, all the education... The visual in the making of the educational space through history. Programme and abstract book of the XXth International Standing Conference for the History of Education (Leuven: ISCHE, 1998).

7 C. Sanchidrián Blanco, "El uso de imágenes en la investigación histórico-educativa", Revista de Investigación Educativa 29, No. 2 (2011): 300 . 
4. Trabajos relacionados con la imagen de los maestros, la que se ofrece de ellos, la que ellos tenían de sí mismos y cómo eran vistos [...].

En España el recorrido se inicia en 2003, dentro del XII Coloquio sobre Historia de la Educación con una sección titulada "Iconografía y Educación" y se ha completado, en gran medida, con el monográfico recogido en la revista Educació $i$ Història $a^{8}$ sobre "Fotografía e Historia de la Educación". Se ha criticado que los estudios sobre fotografía escolar siguen una metodología meramente descriptiva, basada más en el descubrimiento que en el análisis, según han apuntado, entre otros, Fischmann ${ }^{9}$, Viñao ${ }^{10}$ o Montilla Salas ${ }^{11}$. Sin embargo, ya se han iniciado investigaciones analíticas, como muestra el estudio de Sureda García y Comas Rubi $^{12}$ sobre las Colonias de Verano de Can Tàpera en Baleares. Sin duda, se hace necesario el conocimiento y la fijación de las fuentes antes de su análisis, ya que sin la fijación y rastreo de las fuentes documentales existentes no es posible el estudio histórico pretendido.

No son pocas las aportaciones que en este sentido se han llevado a cabo ya en todo el ámbito iberoamericano. Ponemos por caso el trabajo de Comas, Motilla y Sureda ${ }^{13}$ sobre las colonias escolares de la Diputación Balear a principios del siglo XX; o los trabajos de Rosa Fátima de Souza ${ }^{14}$ en Campinas (Brasil), con imágenes desde el siglo XIX a mediados del XX; o bien el rescate de Ramos Escobar ${ }^{15}$ en San Luis Potosí (Méjico). Citamos asimismo otros trabajos contemporáneos como el de Cecilia Gallardo sobre las escuelas de Santiago del Estero, hace apenas una década ${ }^{16}$. Si bien, como titulan Aguilò Ribas, Mulet Gutiérrez y Pinya Llinás ${ }^{17}$, en ocasiones los investigadores han de realizar búsquedas de estas fuentes por archivos generales para rescatar imágenes concretas, en este caso sobre Mallorca entre 1900-1939. Añadimos por último la localización de las principales colecciones existentes que muestra en su trabajo Argerich ${ }^{18} \mathrm{y}$, lo que es más cercano a nuestra aportación, la inclusión de nombres propios de

8 F. Comas, "Fotografía i història de l'educació", Revista d'Història de l'Educació, No. 15 (2010): 11-22.

9 G. E. Fischman, "Las fotos escolares como analizadores en la investigación educativa”, Educaçao e realidade 31, No. 2 (2006): 79-94.

10 A. Viñao, "La historia material e inmaterial de la escuela: memoria, patrimonio y educación”, Educação 35, No. 1 (2012): 7-17.

11 X. Motilla Salas, "Imagen y proyección pública de las colonias escolares de la Menorca de principios del siglo XX. Una aproximación a través del análisis de la prensa y las fotografías", Foro de Educación, No. 13 (2011): 124-125.

12 B. Sureda García y F. Comas Rubí, "La transición en los modelos de la pedagogía del ocio a finales del franquismo a través de fuentes fotográficas: las colonias de verano de Can Tàpera en Baleares”, Revista Lusófona de Educação, No. 25 (2013): $159-176$.

13 F. Comas Rubí, X. Motilla Salas y B. Sureda García, "Iconografía y representación gráfica de las colonias escolares de la Diputación de Baleares. Una aproximación a través del análisis de las fotografías de las memorias”, Revista Española de Pedagogía LXIX, No. 250 (2011): 445-462.

14 R. F. de Souza, “Fotografias escolares: a leitura de imagens na história da escola primária”, Educar, No. 18 (2001): 75 -101.

15 N. Ramos Escobar, "Origen y prospectiva del proyecto Memoria Escolar Fotográfica del Sistema Educativo Estatal Regular en San Luis Potosí", Revista Mexicana de Historia de la Educación 1, No. I (2013): 163-170.

16 N. Arata, "Imágenes de la escuela rural. Apuntes sobre las fotografías de Cecilia Gallardo", Propuesta Educativa, 40 No. 2 (2013): 99-110.

17 C. Aguiló Ribas, M. J. Mulet Gutiérrez y P. Pinya Llinàs, "La fotografia de temàtica escolar en arxius no especialitzats. Notes sobre fons en imatge a Mallorca”, Educació i Història: Revista d'Història de l'Educació, No. 15 (2010): 73-98.

18 I. Argerich, "Imatges fotogràfiques de temàtica educativa en colleccions i arxius públics i privats", Educació $i$ Història: Revista d'Història de l'Educació, No. 15 (2010): 55-72. 
fotógrafos como es el caso del archivo fotográfico de Pedro Brey en Galicia, Val de Omar, etcétera.

\section{Algunos precedentes de la fotografía escolar en Extremadura}

Es innegable el valor como documento que tiene la recuperación del material fotográfico patrimonial de un pueblo, como demuestran las investigaciones en este campo aportadas desde diversos enfoques por Beaumont $\mathrm{Newhall}^{19} \mathrm{o}$ Freund $^{20}$, así como los exhaustivos estudios y análisis de la península que han realizado Lee Fontanella ${ }^{21}$, Sougez ${ }^{22}$, Sánchez Vigil ${ }^{23}$ o López Mondéjar ${ }^{24}$. Asimismo, pueden considerarse clásicos, entre otros, los trabajos de Mario Pedro Díaz Barrado ${ }^{25}$, Gerardo F. Kurtz ${ }^{26}$ y Matilde Muro ${ }^{27}$ sobre la fotografía en general en Extremadura.

Extremadura gozó de fotógrafos de primera fila desde mediados del siglo XIX, con nombres como Charles Clifford ${ }^{28}$ y sus retrospectivas del norte de Cáceres (Alcántara, Plasencia, Jarandilla, Cuacos de Yuste, Yuste) para el Palacio Real (1858 y 1866); Francisco Capdevielle sobre la ciudad de Cáceres; las instantáneas de Gustavo Hurtado Muro y Julián Perate Barroeta en la misma ciudad; Marcial Bocconi en Mérida; Hermenegildo Diéguez en Navalmoral de la Mata; Ángel Garrorena Bernabé o la galería fotográfica de Miguel Olivenza en Badajoz, y un largo etcétera, conjunto que demuestra la existencia de una fotografía de calidad en la región ${ }^{29}$.

Igualmente, la crítica ha testimoniado la existencia de fotógrafos ocasionales que permiten conocer en la actualidad las formas de vida de principios del siglo XX, cuyas instantáneas se engloban en la denominada hora de los aficionados. En este epígrafe se recogen los nombres de Arturo Cerdá y Rico, Dionisio Martínez, Tomás Martín Gil, Emilio Herreros, Tomás Pulido Pulido, Narciso Pérez Zubizarreta, Eduardo Hernández Pacheco, Narciso Martínez Gutiérrez o Santiago Martínez Núñez.

19 B. Newhall, The History of Photography from 1839 to the Present Day (New York: Museum of Modern Art, 1964). B. Newhall, Historia de la fotografía (Madrid: Ed. Gustavo Gili, 2001).

20 G. Freund La fotografía como documento social (Barcelona: Gustavo Gilli, 1976).

21 L. Fontanella, La historia de la Fotografía en España desde sus orígenes hasta 1900 (Madrid: El Viso, 1981). L. Fontanella, Clifford en España: un fotógrafo en la corte de Isabel II (Madrid: El Viso, 1999).

22 M. L. Sougez, 150 años de Fotografía en la Biblioteca Nacional (Madrid: Ministerio de Cultura, Ediciones El Viso, 1989). M. L. Sougez, Historia de la Fotografía (Madrid: Ediciones Cátedra, 1994).

23 J. M. Sánchez Vigil, El documento fotográfico: Historia, usos, aplicaciones (Madrid: Ediciones Trea, 2006).

24 P. López Mondéjar, Fuentes de la Memoria 1. Fotografía y Sociedad en la España del siglo XIX (Madrid: Ediciones Lunwerg, 1989). P. López Mondéjar, Visiones del Deporte. Deporte y Fotografía en España, 1860-1939 (Madrid: Ediciones Lunwerg, 1991).

25 M. P. Díaz Barrado y P. Martínez-Vasseur. La imagen de España y Francia en los medios de comunicación (Cáceres: Universidad de Extremadura, Servicio de Publicaciones, 2003).

26 G. Kurtz e I. Ortega. 150 Años de Fotografía en la Biblioteca Nacional (Madrid: El Viso, 1989).

27 M. Muro, "La fotografía en Extremadura. Tránsito del siglo XIX al XX”, Revista de Estudios Extremeños 55, No. 1 (1999): 137-168. M. Muro, Fotografía en Extremadura hasta 1951 (Mérida: Editora Regional de Extremadura, 2009).

28 L. Fontanella, Clifford en España: un fotógrafo en la corte de Isabel II (Madrid: El Viso, 1999).

29 M. Muro, "La fotografía en Extremadura", Atlántica. Revista de Arte y pensamiento, No. 27 (2000): 120-139. 


\section{Aspectos biográficos de Ezequiel Fernández Santana}

Ezequiel Fernández Santana (Valencia del Ventoso, 1874 - Los Santos de Maimona, 1938) tuvo una amplia formación eclesiástica que se inicia en el seminario conciliar San Atón de Badajoz (1888-1900), donde es ordenado sacerdote. En estos años se matricula en Sevilla (1898-1904), donde consigue el doctorado en Teología. Posteriormente se vincula a Granada (1904-1910) para completar la licenciatura en Derecho Civil y Canónico. Es destinado a tres localidades pacenses como párroco. En primer lugar a San Blas, de Bodonal de la Sierra (19021905); con posterioridad a la parroquia arciprestal de Santa María de Fregenal de la Sierra (1906-1909); y, por último, es destinado a Los Santos de Maimona (1909-1938), estancia que se prolongará hasta su muerte ${ }^{30}$.

Durante este último periodo dirige las instituciones educativas con las que se encontró (primera Enseñanza, bachillerato y estudios de Magisterio), sindicatos agrícolas, cajas de ahorro, bandas de música, ligas militares, escuelas de adultos, y además funda, entre 1914 y 1917, más de veinte escuelas en Extremadura, Andalucía y Castilla y León. Son las siguientes, distribuidas en anualidades: Don Benito, Fregenal de la Sierra, Fuente del Maestre, Sevilla, Valencia del Ventoso y Villalba de Los Barros (1915); Calamonte y Salvaleón (1916); Ahillones, Castuera, La Lapa, Mirandilla, Montánchez, Morera, Valverde del Camino y Zalamea de la Serena (1917); Jaraíz de la Vera (1917/1918); Bienvenida, Cáceres, Malpartida de la Serena, Palenciana y Salamanca (1918); Berlanga, Bodonal de la Sierra, Nogales, Olivenza, Zarza Capilla y Zarza de Alange (1919). Toda esta actividad educativa le impele a difundir su trabajo mediante escritos e imágenes ${ }^{31}$.

En efecto, Fernández Santana tiene una clara concepción divulgativa de sus fundaciones que tiene su reflejo en una extensa y nutrida producción editorial. De una parte cultiva el ensayo. Dentro de este género trata tres temas bien diferentes. Primero, la pedagogía como arma de la acción social: ¿Escuelas o Sindicatos? (1917) y Pedagogía Deportiva (1922). En segundo lugar, la obra Nuestra Escuela (1919), en la que intenta difundir las características de la escuela fundada en Los Santos que la hacen propia y diferente a las del método manjoniano. Por otro lado, dos ensayos de carácter religioso, La Cuestión Social en Extremadura (1935) y El Catecismo Social (1947), en torno a las encíclicas papales Rerum Novarum y Quadragesimo Anno, escritas a modo de comentario en un tono dialogístico. También se acercó al cuento didáctico. Editó un conjunto de relatos breves en un opúsculo titulado Narraciones Apologéticas (1916). Este título pretendió servir de lectura de clase a los alumnos de la escuela parroquial.

Junto a su trabajo editorial desde Los Santos de Maimona, nuestro autor se prodigó como conferenciante. Sus ponencias tuvieron edición impresa en vida, como era habitual en la época. Tenemos constancia de una conferencia dictada en Badajoz sobre los males endémicos del campo extremeño y sus propuestas de

\footnotetext{
30 La primera investigadora que se aproximó a su biografía en profundidad, cuyo estudio recomendamos para una profundización en la misma, fue la de F. Sánchez Pascua, La Obra Socio-Educativa de Ezequiel Fernández Santana (Badajoz: Universitas Editorial, 1994).

31 J. Soto Vázquez, Pedagogía Deportiva (Madrid: Cultiva Comunicación, 2011), 38-50.
} 
solución: Conferencia pronunciada en la Semana Agrícola de Badajoz (1912). También hemos tenido acceso a otra con un tono más divulgativo sobre el método pedagógico de sus escuelas parroquiales, Las Escuelas Parroquiales (1915), junto a otra posterior, Organización y procedimientos pedagógicos en las escuelas parroquiales de Los Santos (1920). En otro discurso abordó la labor que desempeñaban en Extremadura las sociedades de préstamo agrícola, Las Cajas Rurales Extremeñas (1917).

No podemos olvidar su faceta de editor de revistas; por un lado el Boletín Parroquial (1909-1935), con el que pone en conocimiento de sus parroquianos las festividades eclesiásticas y los actos religiosos; por otro lado, Nuestra Escuela (1912), con la que difunde las innovaciones pedagógicas que promueve durante esos años.

En 1915 nace su rotativo La Escuela Parroquial (1915), publicación mensual que se originó como suplemento gratuito del Boletín Parroquial (1912) de enero, pero a partir del no 6, de junio de 1915, se requiere el pago de una suscripción para sufragar los gastos. Las secciones que conformaban la revista eran: Nuestra Escuela, artículos relacionados con la escuela y que dará lugar a la compilación y edición en un solo volumen con ese título; Divulgación Científica, donde se tratan los últimos avances de las distintas disciplinas científicas; Pedagogía Deportiva, exposición del método pedagógico de la escuela parroquial y que también se compila y edita posteriormente; Variedades; La Parroquia y la Escuela, conferencia en la parroquia de San Mateo de Cáceres; Espigando, apartado dedicado a temas de acción social; Crónica, que versa sobre el discurrir de la escuela y sus filiales; De Otras Escuelas, con noticias y acontecimientos de las escuelas filiales; Sección de Anuncios, publicidad y esquelas... La revista aparece ilustrada con fotografías referidas al edificio e instalaciones de la escuela parroquial, filiales o colaboradores.

El siguiente título con imágenes será Pedagogía Deportiva (1922). La obra explica la metodología que deben utilizar los profesores de la nueva escuela propuesta por Fernández Santana, en torno a asignaturas como Lectura, Doctrina Cristiana, Historia de España, Aritmética, Geografía, Agricultura, Geometría y Gramática. Cada una de las lecciones se acompaña del material fotográfico con el que se ilustran las explicaciones pedagógicas, la disposición del aula y ejerci$\operatorname{cios}^{32}$. En 1922 sale a la venta la primera edición de Pedagogía Deportiva, si bien desde 1909 y hasta el año de impresión del título, el propio Fernández Santana implantó en la escuela parroquial de Los Santos de Maimona ciclos de primera enseñanza, segunda enseñanza, un patronato de exalumnos y, por último, un seminario de maestros. La edición se llevó a cabo en la imprenta de los hermanos Sánchez, en Los Santos de Maimona, como texto completo e independiente de La Escuela Parroquial.

Conviene declarar que estas iniciativas no son espontáneas, sino que se unen a las corrientes que desde Europa están impulsando la implantación de la edu-

32 J. Soto Vázquez, Pedagogía Deportiva (Madrid: Cultiva Comunicación, 2011). 
cación física en la escuela ${ }^{33}$. En este sentido, su metodología es una mezcla de la pedagogía lúdica reconocida por las escuelas anglosajonas, y de la instrucción militarista representada por las escuelas alemanas y suecas ${ }^{34}$. Más concretamente, centrándonos en el desarrollo de la disciplina en España, el mayor influjo procedía de la escuela granadina, donde fue instruido y formado por su fundador, Andrés Manjón ${ }^{35}$.

De él hereda su sistema social, el acogimiento de los alumnos pobres, el desarrollo de las habilidades naturales, la escuela fuera del aula o las disposiciones del alumnado que, desde las escuelas de Granada, se difunden al resto de España. La realidad educativa que se encontró Fernández Santana al llegar a Los Santos le sirvió de pretexto para llevar a cabo su proyecto socio-educativo. Se encontró con una población escolar muy amplia y diversa que apenas si acudía con regularidad a clase, un censo de alumnos muy elevado, unido a unas edificaciones en malas condiciones de salubridad, con constantes traslados de locales por no reunir las condiciones higiénicas mínimas. A ello se une el descontento de un profesorado cuyas obligaciones sobrepasaban con creces las impuestas por la administración central, en continua lucha y pleitos con las fuerzas locales, con una situación laboral poco favorable, incrementada por los problemas económicos locales que no daban valor a la educación ${ }^{36}$.

No obstante, el sistema santeño fue únicamente válido para las escuelas de niños, dejando al margen la educación femenina, que no tuvo otra vía de desarrollo que la que el Estado impulsaba en las escuelas normales. En particular, la aplicación de la Pedagogía Deportiva estuvo diseñada para la educación de adultos, a través de las escuelas nocturnas, así como para alumnos de Primera Enseñanza, no continuándose esta metodología en niveles superiores.

Al igual que ocurriera con las escuelas de Granada, el sistema educativo santeño contó rápidamente con una sección de escuelas filiales dispersa por toda la geografía regional y nacional (Córdoba o Salamanca). Se hizo con un amplio número de profesores al frente de estas escuelas nietas, instruidos en el nuevo método, lo cual constituyó el origen de la edición de un conjunto de textos que sirvieron de manual para los docentes. En particular, Pedagogía Deportiva es concebido como el manual teórico y práctico que debían utilizar los docentes que impartieran clases en las escuelas filiales de Los Santos, de ahí la importancia del grueso de los fotogramas que ahora mostramos. En él se combinan los ejercicios prácticos con la recitación teórica, habitual en la época. La organización interna del texto obedece a las materias denominadas como necesarias para completar la educación primaria superior. Si bien solo se recogen diez instantáneas, hubo una cuidadosa selección entre más de 150 fotografías.

33 J. Rodríguez López, Historia del deporte (Barcelona: INDE, 2000), 201 y ss.

34 M. Piernavieja del Pozo, "Francisco Amorós. El primer gimnasiarca español", Citius. Altius. Fortius. II, Fascículo 3, reedición de 1959 (1986): 275-313.

35 F. Sánchez Pascua, La Obra Socio-Educativa de Ezequiel Fernández Santana (Badajoz: Universitas Editorial, 1994).

36 J. Soto Vázquez y A. Samino León, La enseñanza pública en Los Santos de Maimona a través de sus documentos (Badajoz: Diputación de Badajoz, 2014). 


\section{La fotografía escolar de EFS (1915-1938): ubicación de los fondos}

La colección elaborada por Fernández Santana entre 1915 y 1938 supone un material de primera mano sobre este tipo de fotografía, un hito inusual, tanto porque proceden de una misma mano, como por tener casi una única temática: la escuela. Su origen se fecha en agosto de 1915, con la llegada a las escuelas de un proyector cinematográfico Enerman para su uso didáctico en estos términos:

La circunstancia de ser iluminado este cinematógrafo por una pequeña lámpara espiral incandescente de gran potencia lumínica y que produce escaso calor permite detener la película en cada una de sus fases todo el tiempo necesario para explicarla, lo que aumenta su valor pedagógico y hace de él el aparato ideal para la enseñanza (La Escuela Parroquial, 9, 30 de septiembre de 1915: 5).

El conjunto fotográfico se halla disperso en dos colecciones distintas, las cuales se mostraron conjuntamente en $2011^{37}$. De un lado tenemos un conjunto de cajas conservadas por la Fundación Maimona, en Los Santos de Maimona, así como un segundo conjunto de imágenes custodiadas por sus familiares más directos en La Parra, ambas en la provincia de Badajoz (España). Dichos depósitos se componen de un total de 220 fotografías en cristal, las cuales se han catalogado, según se podrá apreciar a continuación.

El grupo de negativos que está en posesión de la Fundación Maimona ha sido recuperado recientemente. El hallazgo de los negativos fotográficos en cristal se produjo de forma casual, gracias al sentido de responsabilidad y sensibilidad de un obrero de la limpieza de Los Santos que los encontró depositados en un contenedor de basura, cercano a la que fuera la casa de su coadjutor, el Padre Luis. En total son 138 cristales con imágenes en negativo. Posteriormente el Patronato de la Fundación Maimona, que las conserva, las positivó. Se encargó de la tarea Santiago Poves Verde (vicepresidente de la Fundación Maimona), junto con la colaboración técnica de José María Ballester.

De otro lado, sus familiares Salud Vega Ruiz y Carmen Ruiz Fernández conservan otras tres cajas con más de 82 placas que han sido igualmente positivadas por José María Ballester Ballester, gracias a la ayuda y financiación de la Fundación Maimona.

Por último, en estos momentos estamos reuniendo y catalogando aquellas imágenes de las que tenemos constancia que, sin embargo, no hemos podido localizar en cristal hasta la fecha. El conjunto se compone de 26 fotografías, entre las que no se han incluido otras relativas a la entrada de tropas franquistas en la población por estar alejadas del ámbito de la educación. La clasificación pretende aportar información sobre los personajes incluidos en la imagen, así como la datación del momento, su ubicación y aquellos aspectos que puedan ser de interés para su clasificación. Por su temática se pueden clasificar en los siguientes epígrafes (Apéndice fotográfico 1): familiares; el edificio escolar; la metodología

37 J. Soto Vázquez y A. Pantoja Chaves, Catálogo de la exposición La fotografía escolar de Ezequiel Fernández Santana (1915-1938” (Los Santos de Maimona: Fundación Maimona, 2011). 
didáctica; la prensa ilustrada: ilustraciones de Pedagogía Deportiva; banda de música; liga militar; escuelas filiales; actos y celebraciones.

\section{Clasificación de la producción fotográfica recuperada}

Tras la localización del corpus total de fuentes se ha procedido a la recuperación y catalogación del mismo. En primer lugar, realizamos una actuación externa, con la medición externa de cada una de las cajas, que también fueron fotografiadas; se hizo copia de los textos que incluía cada una de ellas, la medición de cada uno de los cristales que las componían y la copia de los textos que acompañaban a las imágenes. En segundo lugar se procedió a la digitalización y restauración técnica de las imágenes más deterioradas en el estudio fotográfico. El conjunto fue trasladado a Badajoz para su digitalización en el estudio fotográfico de José María Ballester, quien realizó la limpieza de las piezas dañadas y el escaneado de todas las placas fotográficas. Por cuestiones de espacio dejaremos al margen detalles técnicos que superarían las dimensiones de este artículo (Apéndice fotográfico 2). En último lugar se han tenido en cuenta los criterios fijados por Sánchez ${ }^{38}$ para la elaboración de una fototeca digital, quien ha establecido una serie de criterios de selección para la constitución de un fondo fotográfico, como son la antigüedad, temática, originalidad, identificación, calidad técnica y cantidad. También se han tenido en cuenta dos distintas formas de ingreso de fondos fotográficos: creación de registros y revisión de los mismos de Hernández, Sánchez y Tercero ${ }^{39}$. Y, por último, también se consideraron las indicaciones que marcan en su exhaustiva catalogación Ibáñez, López, Sánchez y Villalón para el CSIC ${ }^{40}$, así como el modelo de ficha de catalogación propuesto por Félix del Valle ${ }^{41}$. Los criterios de todas estas aportaciones se han tenido en cuenta, si bien hemos optado finalmente por una modificación propia que se ajusta a la naturaleza de nuestro material, como puede observarse en el Apéndice fotográfico de este estudio.

Tras el proceso de digitalización, se elaboró la base de datos y la versión multimedia desarrollada posteriormente en FileMaker, para lo cual ha sido necesaria una segunda búsqueda bibliográfica que nos ayudara a datar las imágenes o explicar sus contenidos. En este sentido, han sido de gran utilidad los fondos de la Biblioteca Pública de Los Santos de Maimona, el Archivo Municipal y el Archivo Parroquial, así como archivos privados de antiguos alumnos de las escuelas. En algunas imágenes se ha podido localizar hasta el día y hora en que se

38 J. M. Sánchez, “Centros de documentación fotográfica: Fototecas, Archivos y Colecciones en España”, en Manual de Documentación Fotográfica, editado por F. del Valle (Madrid: Editorial Síntesis, 1999), 24-25.

39 L. Ma Hernández, Ma I. Sánchez y A. B. Tercero, "La vida universitaria documentada: la fototeca digital de la Universidad de Castillala Mancha (Ciudad Real, España)", en Actas de las XI Jornadas de Gestión de la Información (Madrid: SEDIC, 2009), 255-260.

40 R. Ibáñez González et al., "El archivo fotográfico en la Unidad de Tratamiento Archivístico y Documentación (UTAD) del Centro de Ciencias Humanas y Sociales del CSIC", en XI Jornadas de Gestión de la Información: Servicios polivalentes, confluencia entre profesionales de archivo, biblioteca y documentación (Madrid: Sociedad Española de Documentación e Información Científica, 2009), 6.

41 F. del Valle, "El análisis documental de la fotografía", en Manual de Documentación Fotográfica (Madrid: Editorial Síntesis, 1999), 129. 
produjo el suceso que narra la fotografía, en otras, sin embargo, tan solo ha sido posible informar del año y, en las menos, no tenemos ninguna información que detallar, como ha sucedido con los retratos familiares (Apéndice fotográfico 3).

Tabla I. Fondo fotográfico de la Fundación Maimona (caja 1)

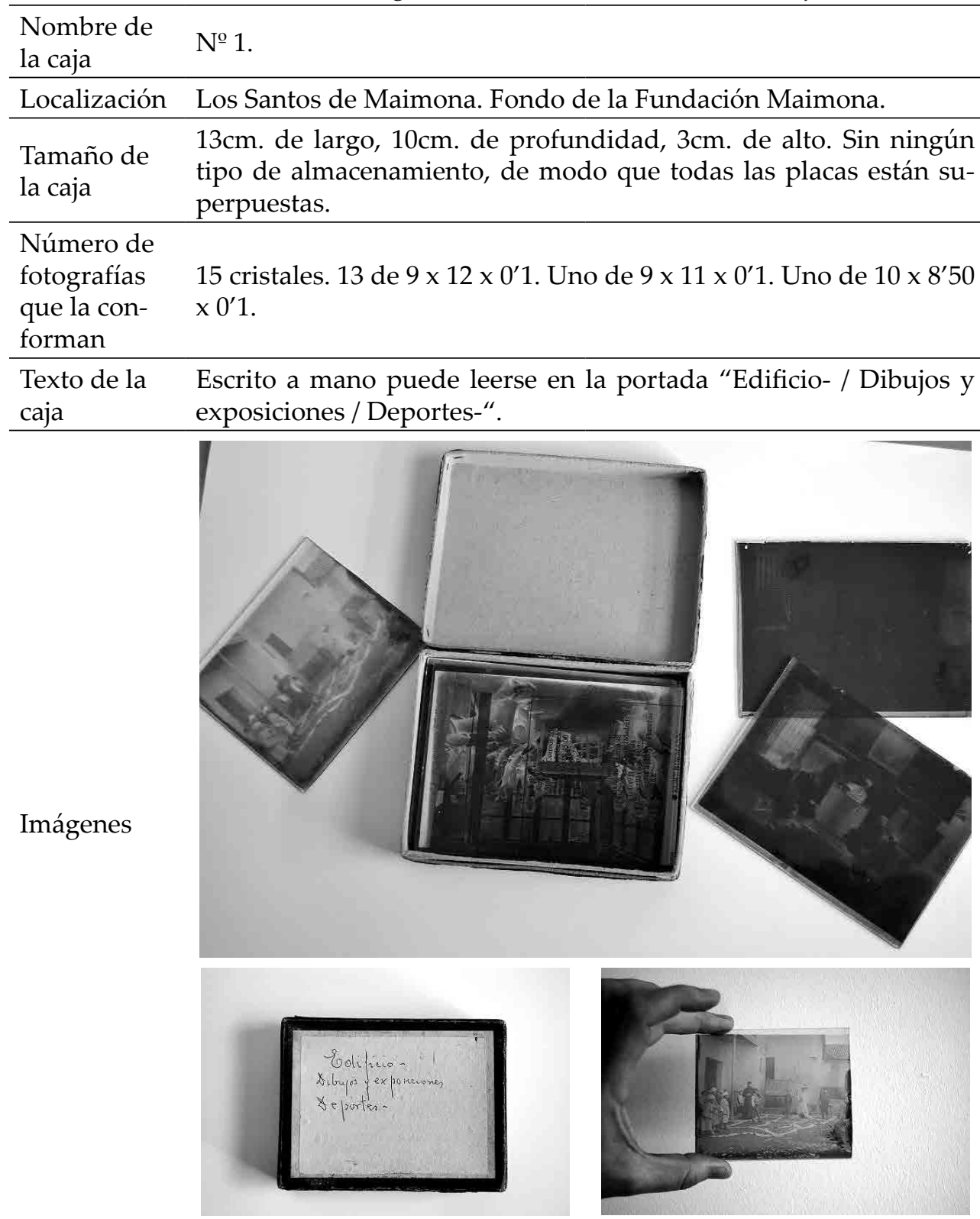


Tabla II. Fondo fotográfico de la Fundación Maimona (caja 2)

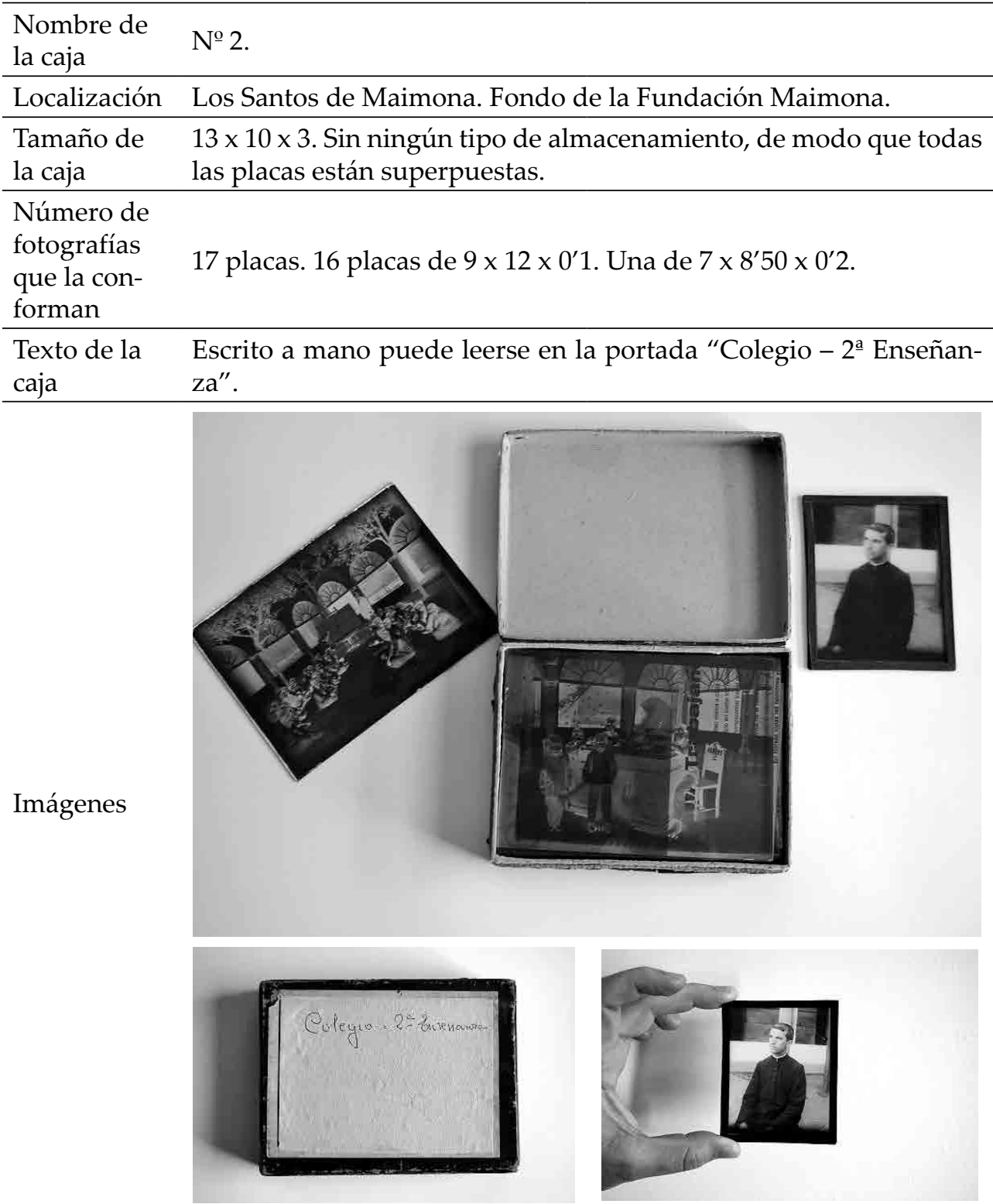


Tabla III. Fondo fotográfico de la Fundación Maimona (caja 3)

\begin{tabular}{|c|c|}
\hline $\begin{array}{l}\text { Nombre de la } \\
\text { caja }\end{array}$ & № 3 . \\
\hline Localización & Los Santos de Maimona. Fondo de la Fundación Maimona. \\
\hline $\begin{array}{l}\text { Tamaño de la } \\
\text { Caja }\end{array}$ & $\begin{array}{l}13 \times 10 \times 3 \text {. Sin ningún tipo de almacenamiento, de modo que to- } \\
\text { das las placas están superpuestas. }\end{array}$ \\
\hline $\begin{array}{l}\text { Número de } \\
\text { fotografías } \\
\text { que la confor- } \\
\text { man }\end{array}$ & 15 placas. Catorce de $9 \times 12 \times 0^{\prime} 1$. Una de $9 \times 12 \times 0$. 2 \\
\hline $\begin{array}{l}\text { Texto de la } \\
\text { caja }\end{array}$ & $\begin{array}{l}\text { Escrito a mano puede leerse en la portada: "Escuela nocturna / y } \\
\text { Sindicato". En la contraportada aparece el nombre de la casa foto- } \\
\text { gráfica que suministra las placas: "LUMIÈRE \& JOUGLA". Núme- } \\
\text { ro de referencia "X- } 48802 \text { ". }\end{array}$ \\
\hline
\end{tabular}

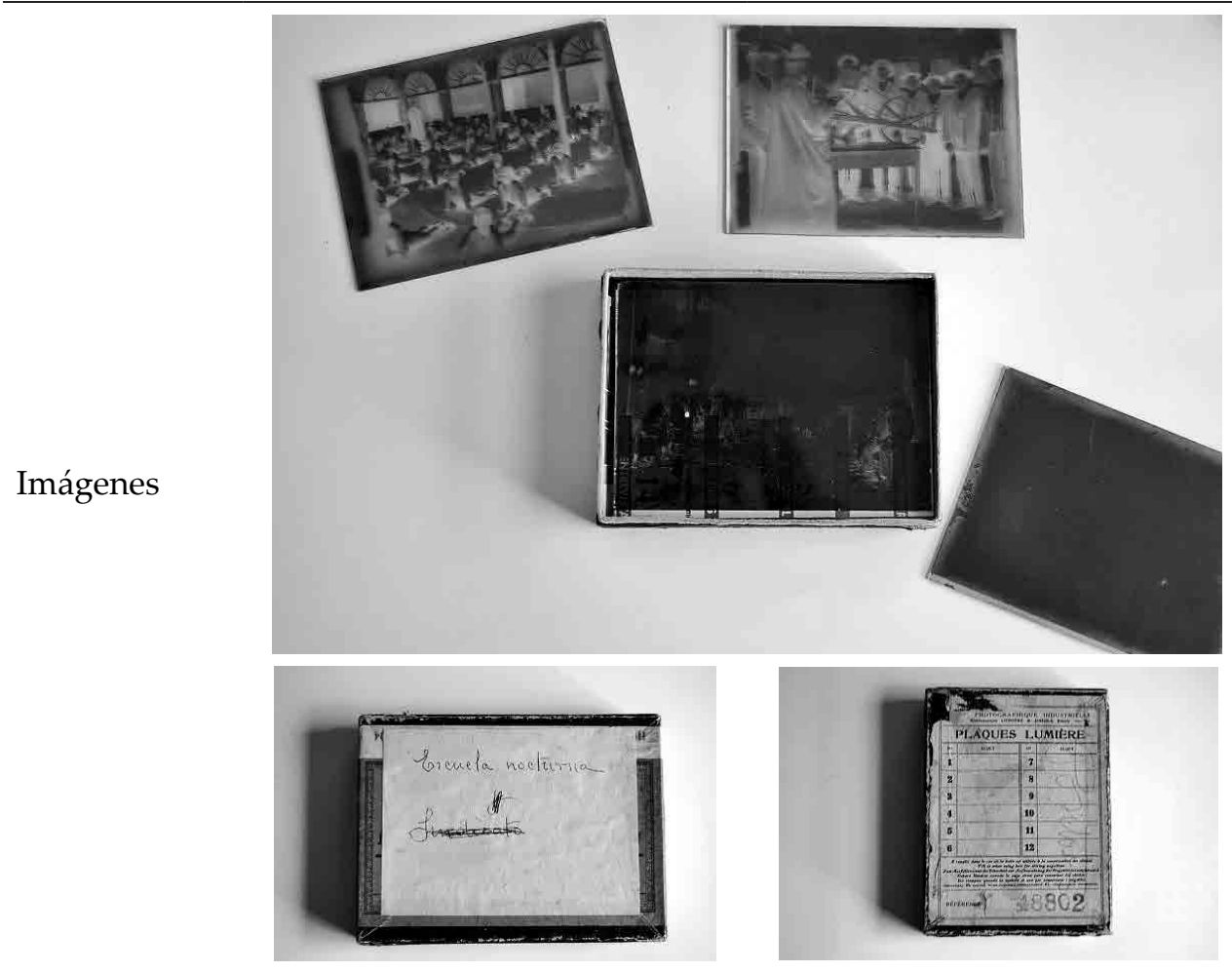


Tabla IV. Fondo fotográfico de la Fundación Maimona (caja 4)

\begin{tabular}{ll}
\hline $\begin{array}{l}\text { Nombre de la } \\
\text { caja }\end{array}$ & № 4. \\
\hline Localización & Los Santos de Maimona. Fondo de la Fundación Maimona. \\
\hline $\begin{array}{l}\text { Tamaño de la } \\
\text { caja }\end{array}$ & $\begin{array}{l}13 \times 10 \times 3 . \text { Sin ningún tipo de almacenamiento, de modo que to- } \\
\text { das las placas están superpuestas. }\end{array}$ \\
\hline $\begin{array}{l}\text { Número de } \\
\text { fotografías } \\
\text { que la confor- } \\
\text { man }\end{array}$ & \begin{tabular}{l}
15 cristales. Ocho de $9 \times 12 \times 0^{\prime} 1$. Cuatro de $9 \times 12 \times 0$ Otro de $8^{\prime} 50 \times 8^{\prime} 50$. \\
\hline
\end{tabular}
\end{tabular}
Texto de la superior derecho: “Colegio - 1 $1^{\text {a }}$ Enseñanza”. En la contraportada caja aparece el nombre de la casa fotográfica que suministra las placas: "LUMIÈRE \& JOUGLA". Número de referencia “X - 48802".

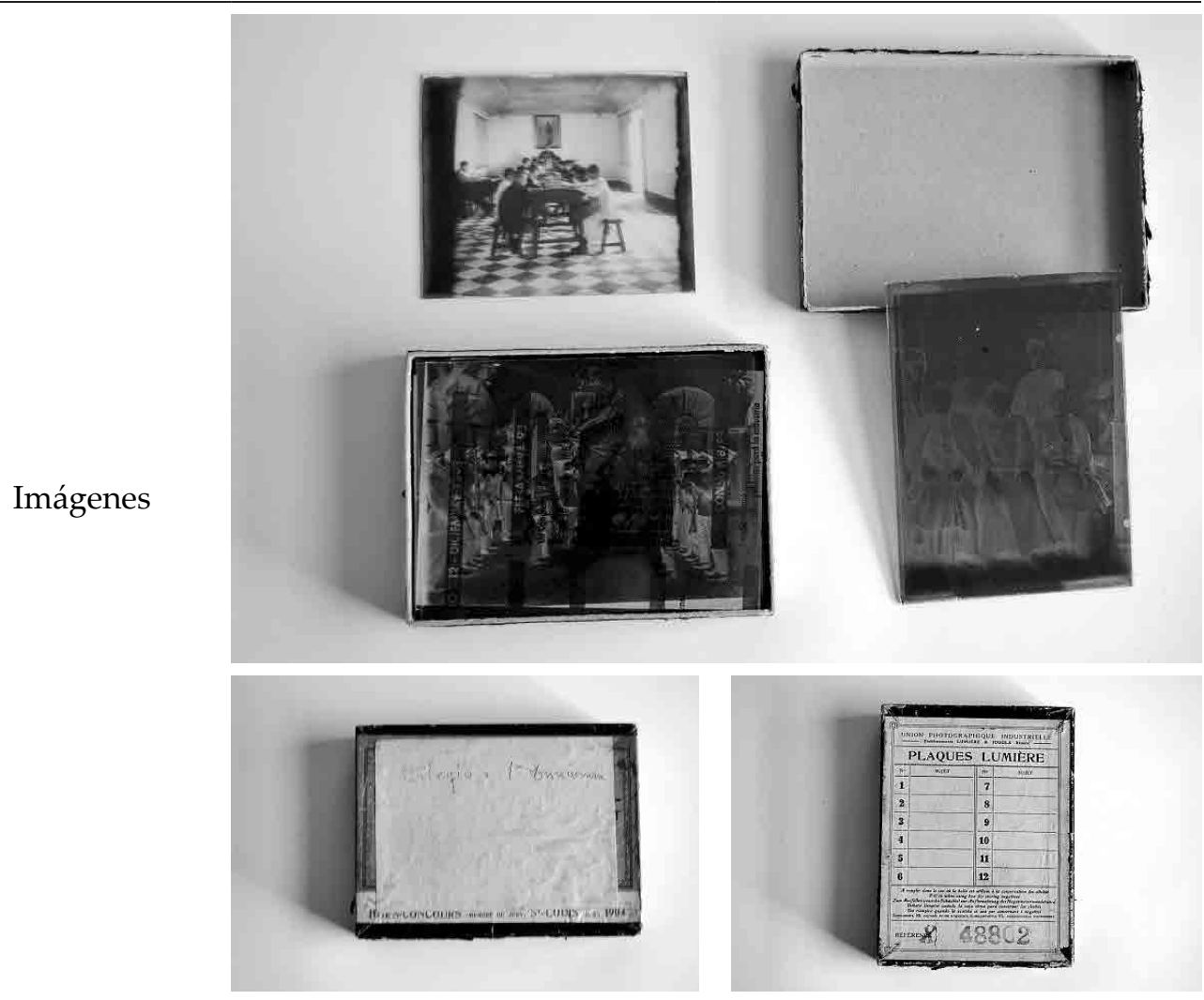


Tabla V. Fondo fotográfico de la Fundación Maimona (caja 5)

Nombre de la $\quad$ № 5 .

caja

\begin{tabular}{ll}
\hline Localización & Los Santos de Maimona. Fondo de la Fundación Maimona. \\
\hline $\begin{array}{ll}\text { Tamaño de la } \\
\text { caja }\end{array}$ & $\begin{array}{l}13 \times 10 \times 3 . \text { Sin ningún tipo de almacenamiento, de modo que } \\
\text { todas las placas están superpuestas. }\end{array}$ \\
\hline $\begin{array}{l}\text { Número de } \\
\text { fotografías que } \\
\text { la conforman }\end{array}$ & 9 cristales. Ocho de $9 \times 12 \times 0$ '1. Uno de $9 \times 12 \times 0$ '2. \\
\hline \begin{tabular}{l} 
Texto de la caja \\
Escrito a mano puede leerse en la portada: "Edificio y / Vista \\
\hline
\end{tabular} &
\end{tabular}


Tabla VI. Fondo fotográfico de la Fundación Maimona (caja 6)

Nombre de la № 6 .

caja

\begin{tabular}{ll}
\hline Localización & Los Santos de Maimona. Fondo de la Fundación Maimona. \\
\hline $\begin{array}{ll}\text { Tamaño de la } \\
\text { caja }\end{array}$ & $\begin{array}{l}13 \times 10 \times 3 . \text { Sin ningún tipo de almacenamiento, de modo que } \\
\text { todas las placas están superpuestas. }\end{array}$ \\
\hline $\begin{array}{l}\text { Número de } \\
\text { fotografías que } \\
\text { la conforman }\end{array}$ & $\begin{array}{l}\text { Escrito a mano puede leerse en la portada: “Sindicato". En la con- } \\
\text { traportada solo aparece un número de referencia: “08936”. }\end{array}$ \\
\hline Texto de la caja $12 \times 0$ '. Dos de $9 \times 12 \times 0$ '2.
\end{tabular}


Tabla VII. Fondo fotográfico de la Fundación Maimona (caja 7)

\begin{tabular}{ll}
\hline $\begin{array}{l}\text { Nombre de la } \\
\text { caja }\end{array}$ & № 7. \\
\hline Localización & Los Santos de Maimona. Fondo de la Fundación Maimona. \\
\hline $\begin{array}{l}\text { Tamaño de la } \\
\text { caja }\end{array}$ & $\begin{array}{l}13 \times 10 \times 3 \text {. Sin ningún tipo de almacenamiento, de modo que } \\
\text { todas las placas están superpuestas. }\end{array}$ \\
\hline $\begin{array}{l}\text { Número de } \\
\text { fotografías que } \\
\text { la conforman }\end{array}$ & 18 cristales. Diecisiete de $9 \times 12 \times 0$ × 1. Uno de $9 \times 12 \times 0$ '2. \\
\hline Texto de la caja & $\begin{array}{l}\text { Tiene un rótulo de la casa fotográfica, en la que puede leerse } \\
\text { “UNION PHOTOGRAPHIQUE INDUSTRIELLE / INSTAN- } \\
\text { TANÉES / MARQUE / J. JOUGLA”. }\end{array}$ \\
\hline
\end{tabular}

Imágenes

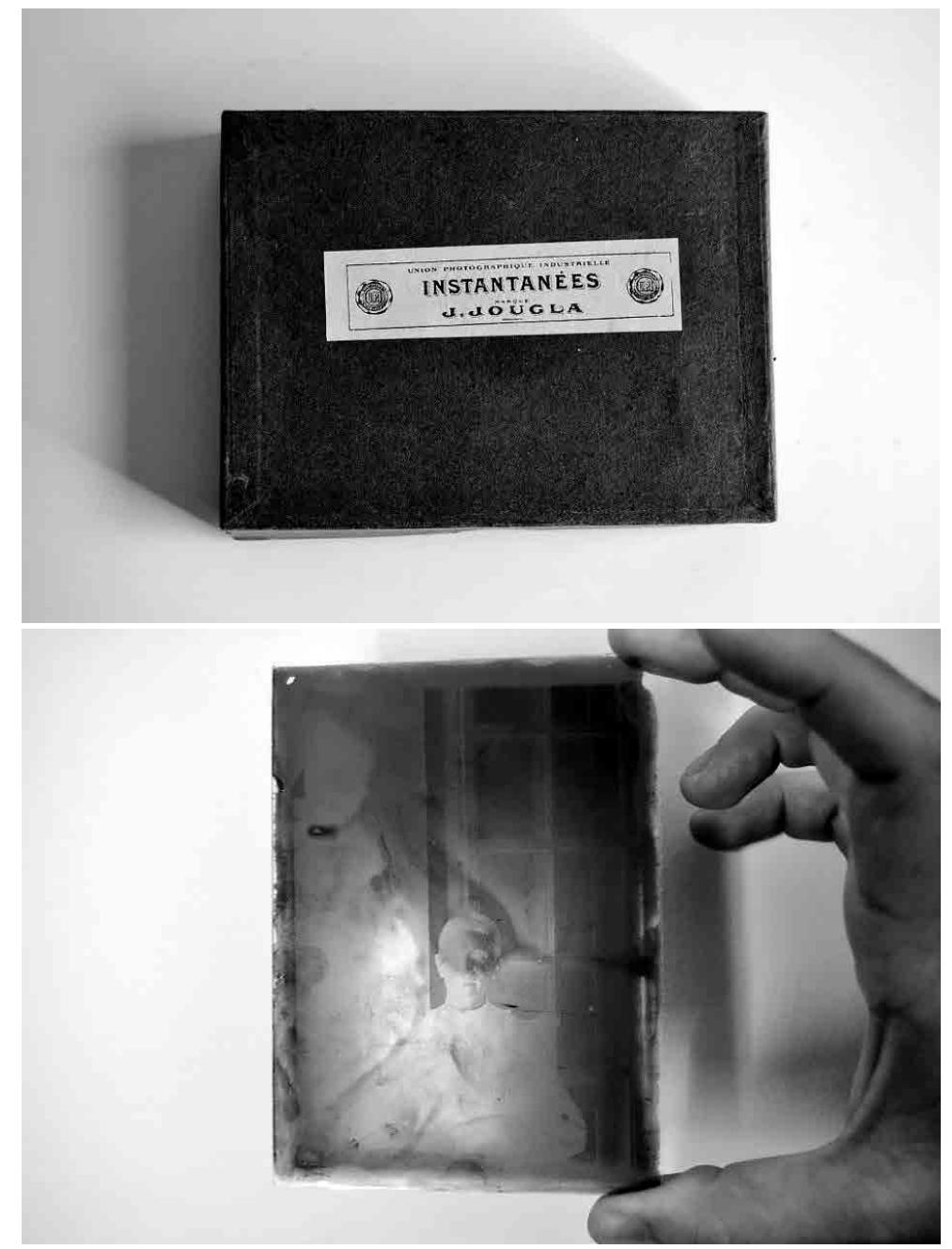


Tabla VIII. Fondo fotográfico de la Fundación Maimona (caja 8)

Nombre de la $\quad$ № 8 .

caja

Localización Los Santos de Maimona. Fondo de la Fundación Maimona.

Tamaño de la $13 \times 10 \times 3$. Sin ningún tipo de almacenamiento, de modo que caja todas las placas están superpuestas.

Número de 13 cristales. Nueve de $9 \times 12 \times 0$ 0'1. Uno de $9 \times 12 \times 0$ 0'2. Uno de fotografías que $\quad 10^{\prime} 50 \times 8 \times 0^{\prime} 1$. Dos de 8'50 × 8'50 x0'1.

la conforman

Texto de la caja Tiene un sello de la casa fotográfica "LUMIÈRE \& J. JOUGLA". Es una caja de almacenamiento de placas fotográficas de Bromuro de plata de 9 x 12. № de fabricación: "12289".

Imágenes
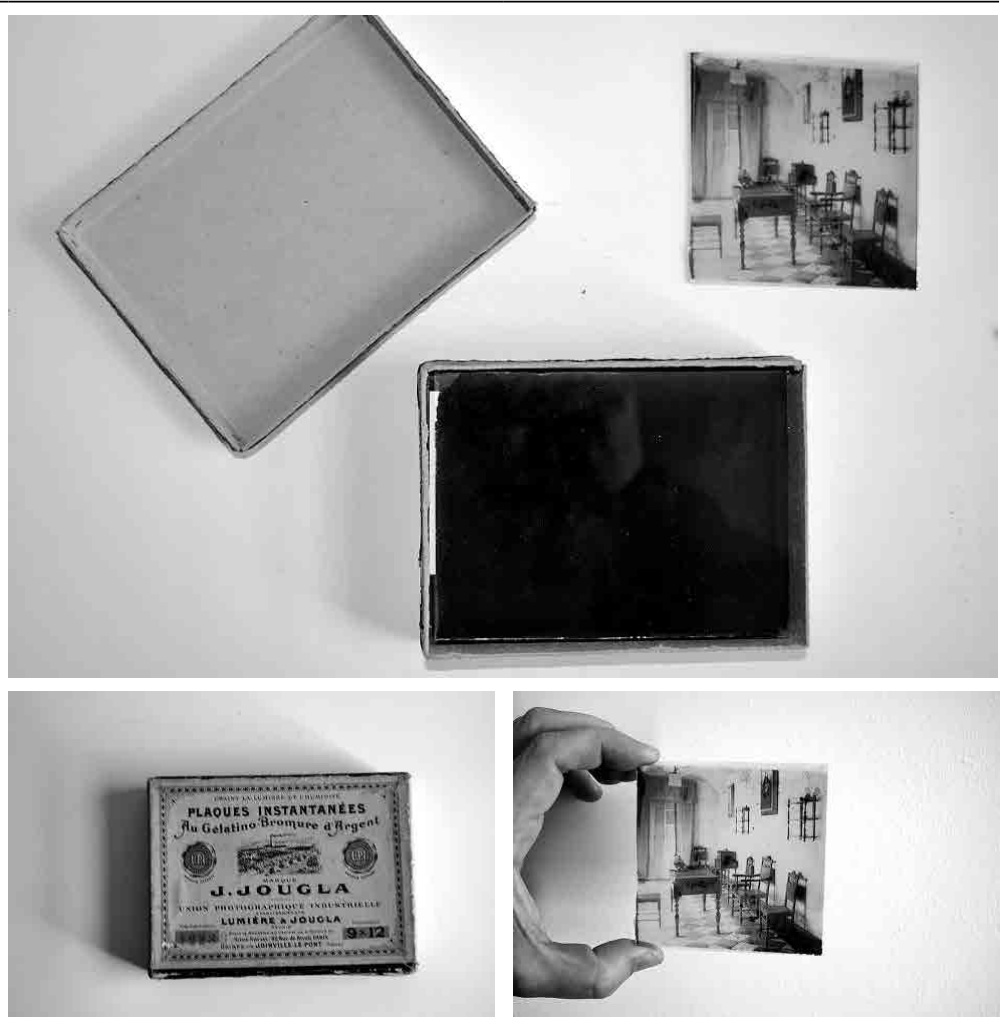
Tabla IX. Fondo fotográfico de la Fundación Maimona (caja 9)

Nombre de la № 9 .

caja

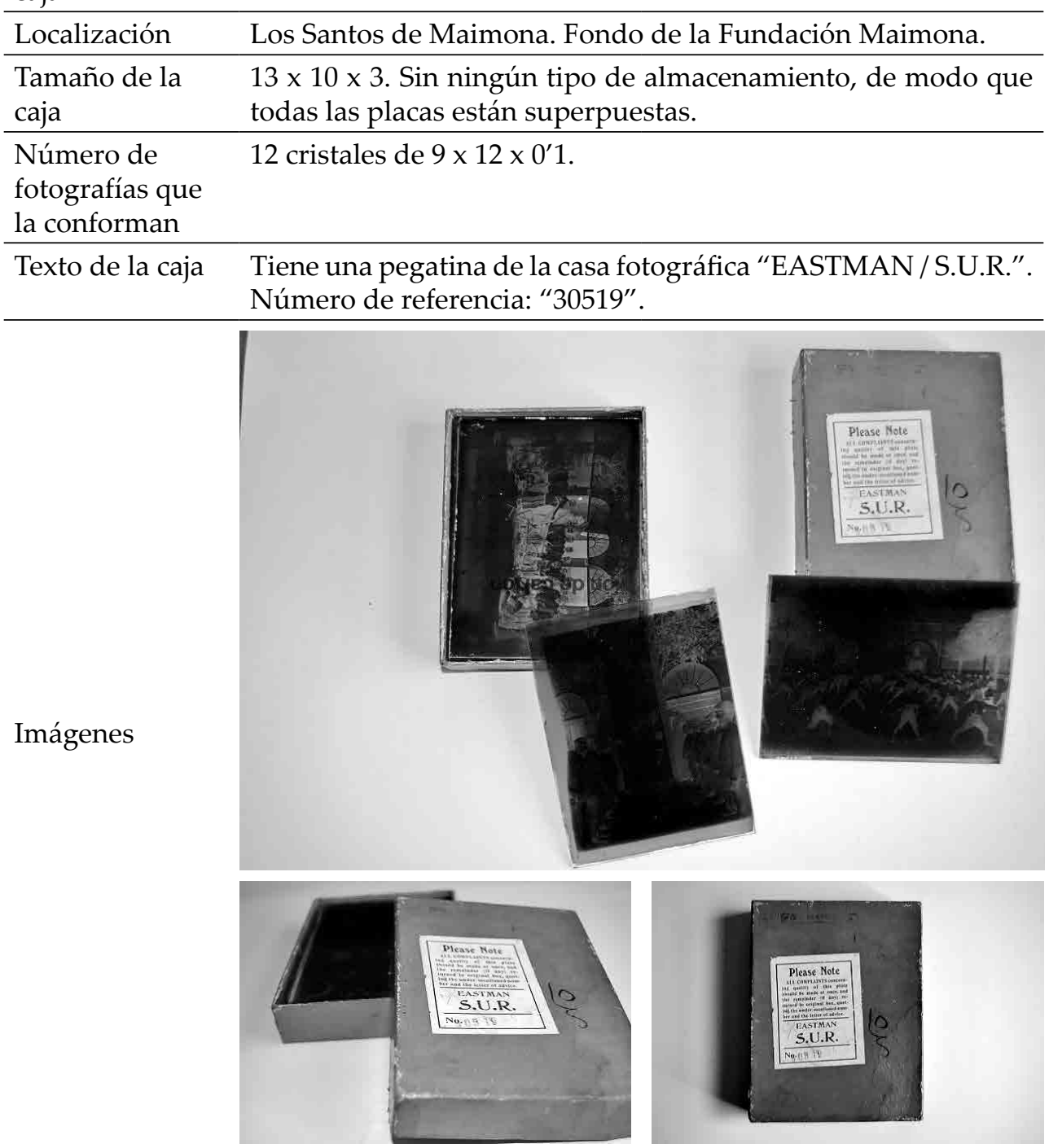


Tabla X. Fondo fotográfico de la Fundación Maimona (caja 10)

Nombre de la № 10 .

caja

\begin{tabular}{ll}
\hline Localización & Los Santos de Maimona. Fondo de la Fundación Maimona. \\
\hline Tamaño & $\begin{array}{l}15 \text { de largo, } 10 \text { de profundidad, } 2 \text { de alto. Sin ningún tipo de } \\
\text { almacenamiento, de modo que todas las placas están super- } \\
\text { puestas. }\end{array}$ \\
\hline $\begin{array}{l}\text { Número de } \\
\text { fotografías que } \\
\text { la conforman }\end{array}$ & $\begin{array}{l}7 \text { cristales de } 9 \times 14 \times 0^{\prime} 1 . \text { Ocho tarjetas postales en negativo de } \\
14 \times 80 . \text { Una postal de } 12 \times 10 . \text { Dos postales más de } 9 \times 9^{\prime} 50 .\end{array}$ \\
\hline
\end{tabular}

Texto de la caja Tiene un rótulo de la casa fotográfica "AGFA". Es una caja de almacenamiento de placas fotográficas de Bromuro de Plata de $9 \times 14$. № de fabricación: 6/55. Tiene un timbre móvil de correos de 25 céntimos.

En la contraportada se recogen las instrucciones de revelado de las placas, con el uso de "Rodinal".

Imágenes
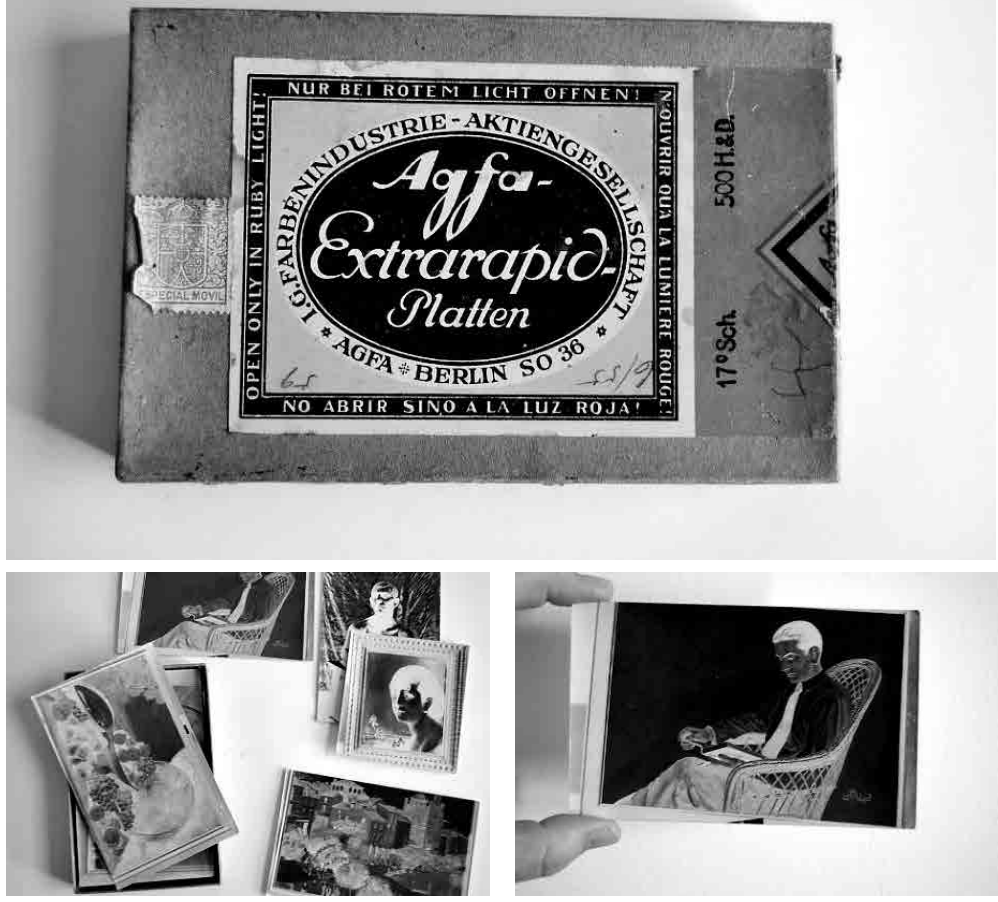
Tabla XI. Fondo fotográfico familia de Ezequiel Fernández Santana (caja 1)

Nombre de la $\quad$ № 1 .

caja

Localización La Parra. Herederos de Ezequiel Fernández Santana.

\begin{tabular}{|c|c|}
\hline $\begin{array}{l}\text { Tamaño de la } \\
\text { caja }\end{array}$ & $\begin{array}{l}22^{\prime} 5 \times 11^{\prime} 5 \times 11^{\prime} 5 \text { de profundidad. } \\
\text { El interior está compuesto por } 30 \text { ranuras en las que se incluyen } \\
\text { las placas, fabricado en marquetería. }\end{array}$ \\
\hline $\begin{array}{l}\text { Número de } \\
\text { fotografías que } \\
\text { la conforman }\end{array}$ & $\begin{array}{l}\text { Conforman la caja } 30 \text { cristales de } 10 \times 8^{\prime} 50 \times 0 \text { × } 3 \text {, forrados con } \\
\text { adhesivos de color negro en los bordes y un distintivo en el que } \\
\text { se enumeran. Todas las imágenes contenidas son instantáneas } \\
\text { de las escuelas de los Santos. } \\
\text { Todas tienen la misma medida, excepto la del Sagrado Corazón, } \\
\text { numerada como " } 6 \text { ": } 8^{\prime} 5 \times 8^{\prime} 5 \times 0^{\prime} 2 \text {. }\end{array}$ \\
\hline Texto de la caja & 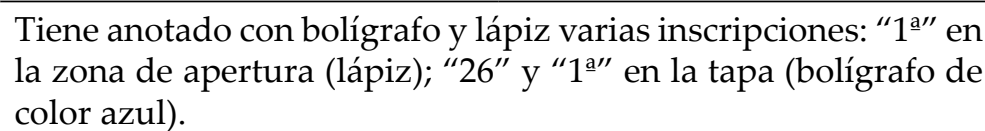 \\
\hline
\end{tabular}

Imágenes
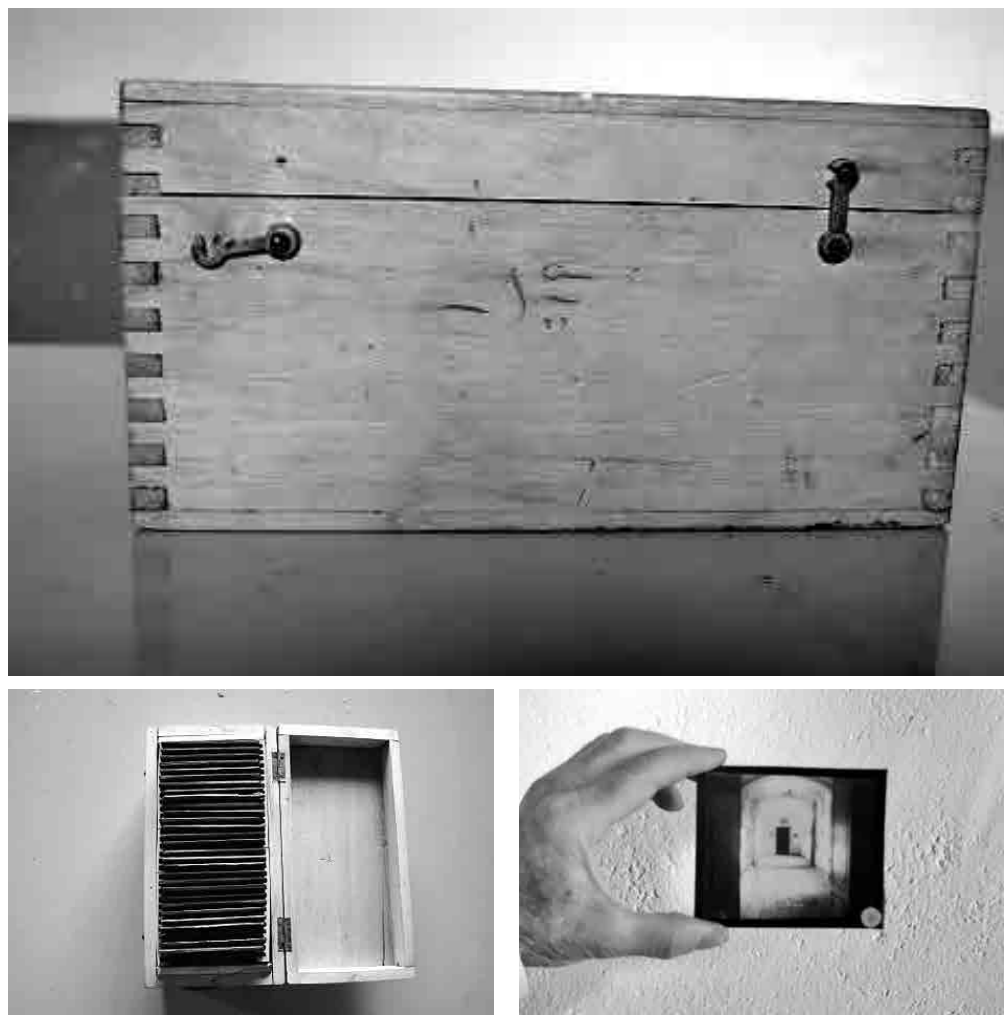
Tabla XII. Fondo fotográfico familia de Ezequiel Fernández Santana (caja 2)

Nombre de la № 2 .

caja

Localización La Parra. Herederos de Ezequiel Fernández Santana.

Fotografías Todas contienen dos inscripciones mecánicas.

A: "PROJECTIONS - MAZO- PARIS / Autorisation de Projeter".

B1: “E. MAZO / PARIS. / №..............". La numeración es manuscrita.

B2: "Serie". Este apartado está completado a mano.

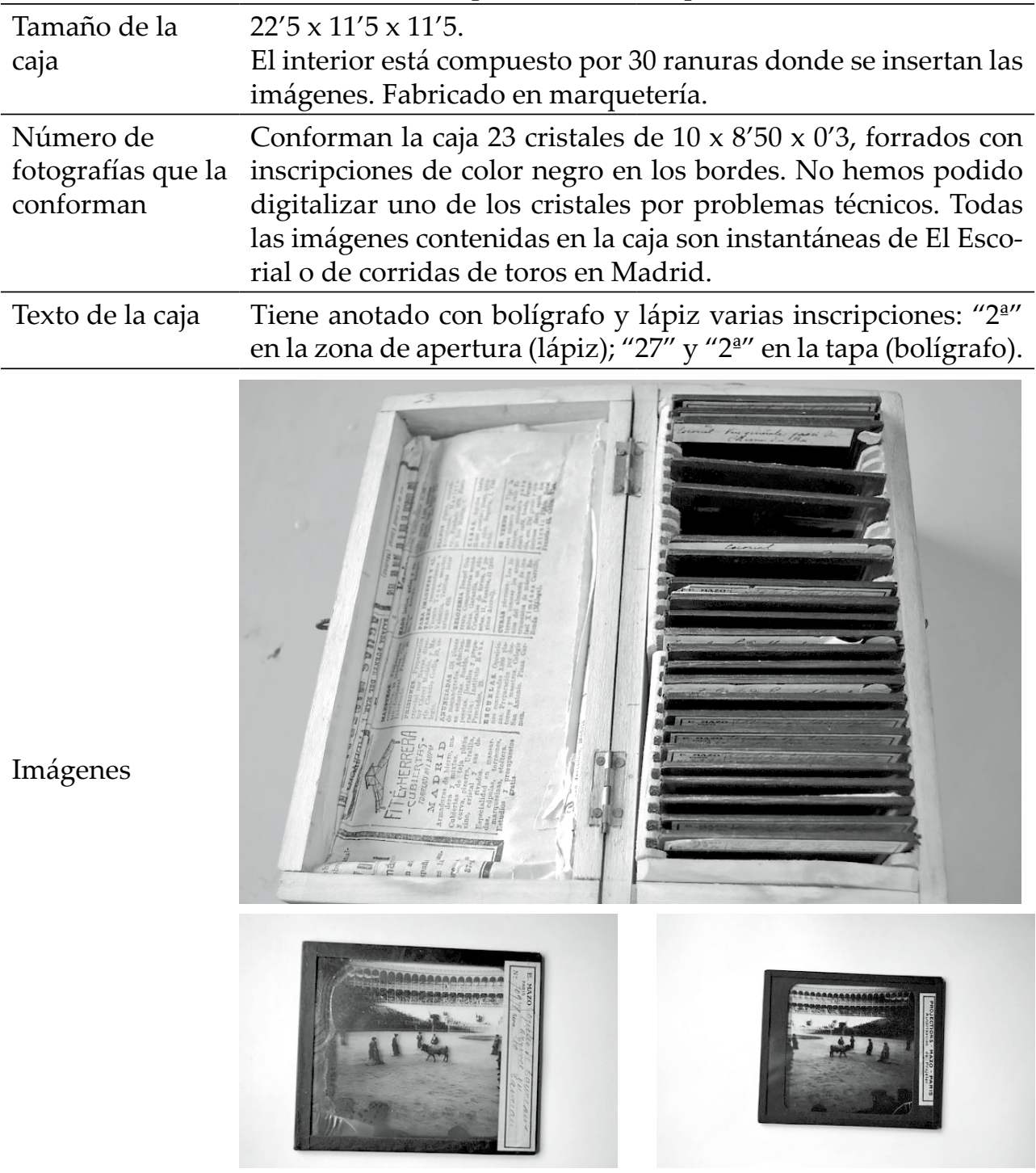


Tabla XIII. Fondo fotográfico familia de Ezequiel Fernández Santana (caja 3)

Nombre de la № 3 .

caja

Localización La Parra. Herederos de Ezequiel Fernández Santana.

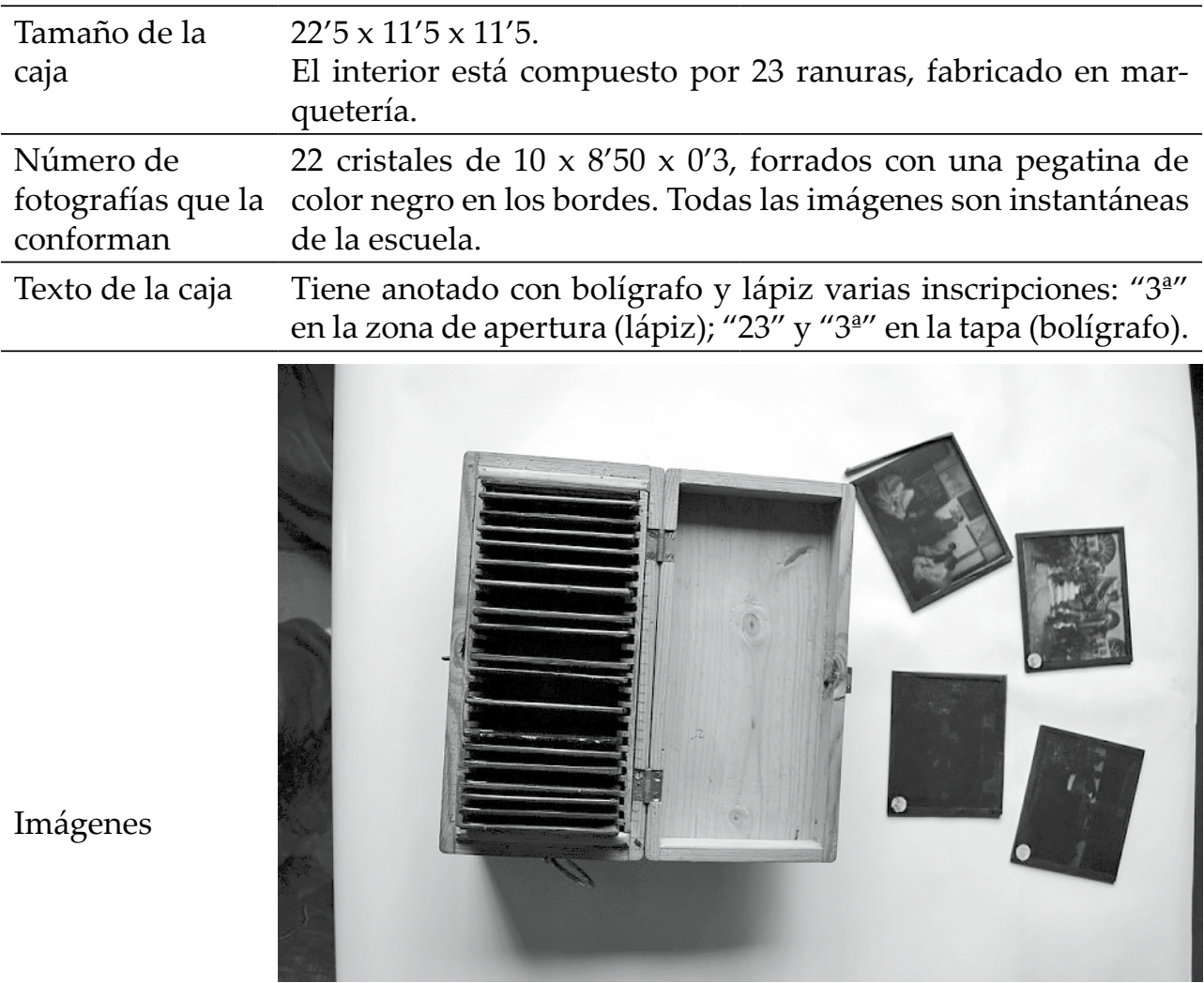
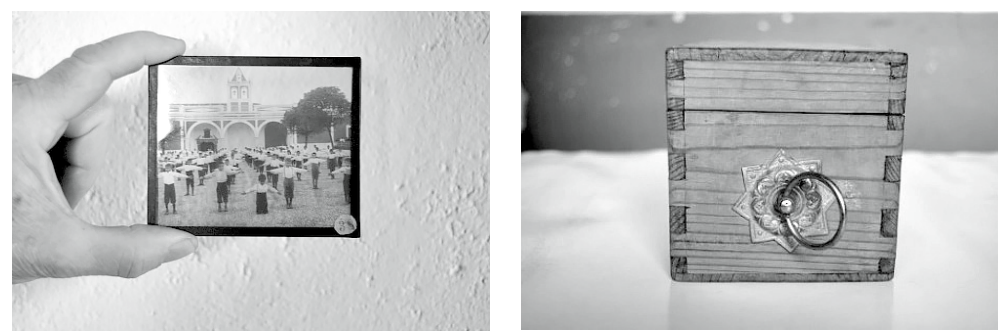


\section{CONCLUSIÓN}

El conjunto rescatado y digitalizado hasta la fecha lo componen 220 placas fotográficas, de las cuales 30 son retratos familiares, 10 son un conjunto de imágenes de El Escorial, 10 son un curso de tauromaquia, y las 170 restantes son instantáneas de las escuelas parroquiales fundadas por Ezequiel Fernández Santana. Estas últimas se subdividen en las siguientes temáticas: autorretratos; maestros de las escuelas; el edificio escolar; representaciones de actividades culturales; exposiciones; clases prácticas y conmemoraciones escolares.

La función de la fotografía escolar de Fernández Santana es la del documentalista como soporte a sus fundaciones escolares. De ahí que con enorme rapidez su trabajo se sume al de los libros ilustrados, y en especial al de la prensa escolar ilustrada, poco usual por entonces en España. Es, sin duda, un caso excepcional, pues no hay cierta regularidad en Extremadura del uso de la edición ilustrada hasta los años treinta, mientras que las primeras impresiones de Fernández Santana datan de 1915. Se trata de una fotografía eminentemente pedagógica, en la que el hecho educativo ocupa el primer plano.

Conviene decir que la mayoría de los testimonios de fotografía escolar en España y Extremadura apenas si pasan de la imagen de conjunto de los grupos escolares en los que los alumnos rodean al docente, a modo de retrato. Podemos hablar, por tanto, de instantáneas anecdóticas que buscan la inmortalidad de los docentes en un intervalo del quehacer diario. Son muy abundantes las fotografías familiares de niños leyendo o posando en actitud académica; sin embargo, no existe una fotografía escolar que refleje estrategias didácticas, y mucho menos de una misma fuente o mano. Al menos, ninguno de los fotohistoriadores la menciona en España, lo que le concede al trabajo de Fernández Santana un valor único, tanto por la calidad y estudio de las impresiones como por el amplio número de placas conservadas.

Respecto al conjunto de instantáneas sobre didácticas específicas resultantes, queda patente la supremacía que Fernández Santana otorga a la enseñanza de la Agricultura (17 fotografías), ya que para él es el verdadero motor de la economía extremeña, y era uno de los males endémicos de la región que habían postergado el desarrollo de Extremadura, debido a la mala distribución de la riqueza y al desconocimiento de las técnicas más productivas. A esta disciplina le sigue Doctrina Cristiana (13 imágenes). Igualmente, considera fundamentales la Lectura y Gramática (12 de ambas disciplinas), pilares sobre las que se sustenta el resto de áreas.

Aunque muy tímidamente, se asoma una intencionalidad artística en la composición. Hay un estudio de la toma, de la iluminación y recreación del momento escolar que se desea captar. De manera que se buscan distintos enfoques para un mismo momento, así como horas de luz distintas o composiciones de los planos en los que se eliminan personajes o instrumentos didácticos. A grandes rasgos, el lector podrá vislumbrar estas intenciones en los diferentes ejemplos simultáneos que se incluyen más abajo. En suma, no podemos hablar de un trabajo espontáneo y casual, sino de un esfuerzo medido y estudiado, casi propagandístico podríamos decir, que repercutiría directamente en la economía del colegio (Apéndice fotográfico 4). 


\section{Apéndice fotográfico}

Figura 1. Apéndice fotográfico 1. Fondo perdido.

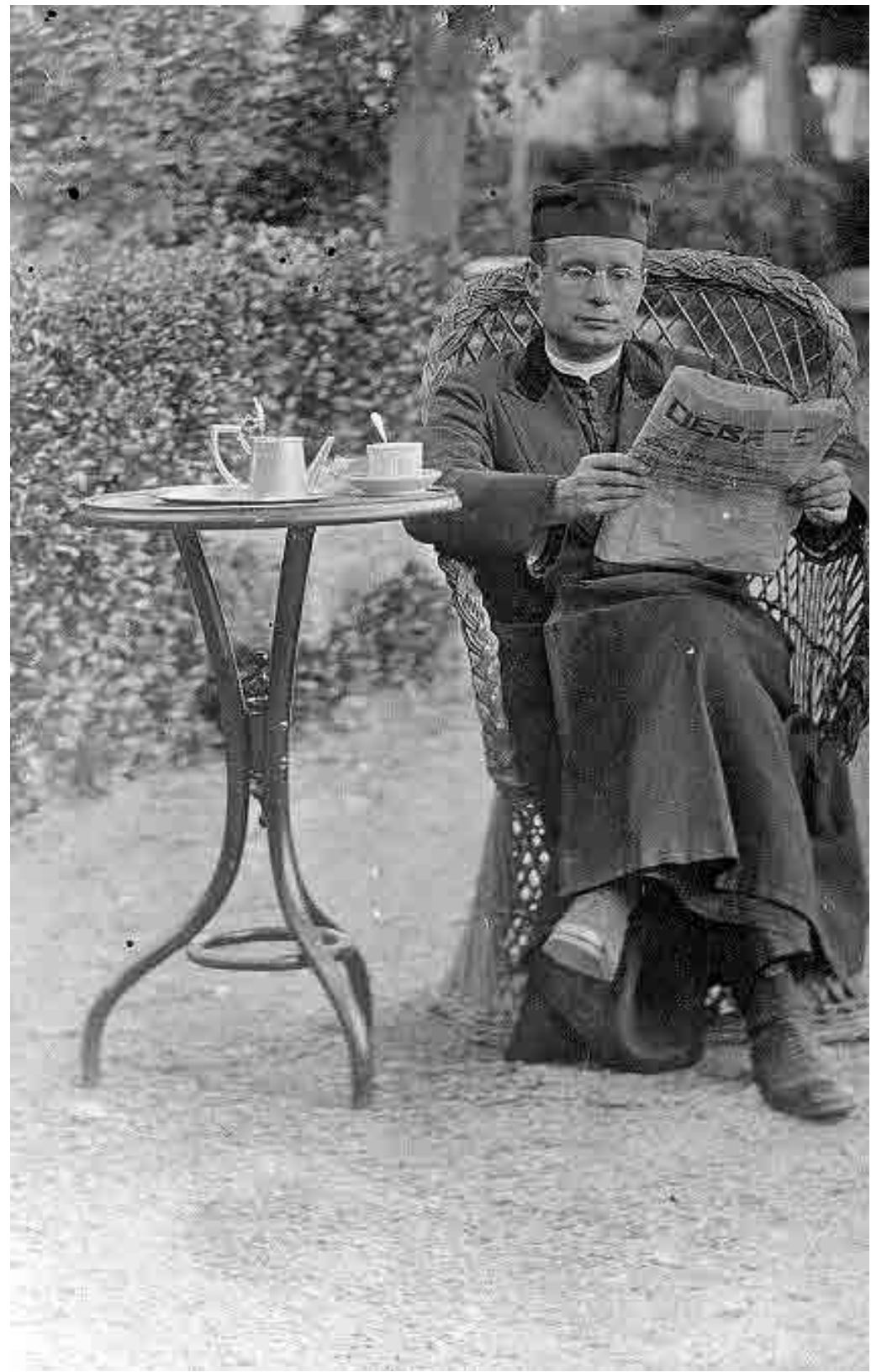

Carta enviada a sus padres y hermanas desde El Escorial, en la que narra el viaje hasta Madrid e informa de su inminente regreso. Sin fecha ni lugar concreto, parece parte un fragmento de otra carta en la que se incluiría. 1915. Vemos 
que está leyendo el periódico El Debate, órgano de difusión del catolicismo social e ideado por el Cardenal Herrera Oria en 1910. El director del periódico, bajo el seudónimo de Curro Vargas realizó una entrevista en Madrid a Ezequiel Fernández Santana para su rotativo en 1915, posible momento de la entrevista. E igualmente, fueron constantes las visitas de redactores del diario a Los Santos: Curro Vargas en 1916, Isidro Almazán en 1917 (Herederos de Ezequiel Fernández Santana. La Parra).

Figura 1. Apéndice fotográfico 1. Fondo perdido.

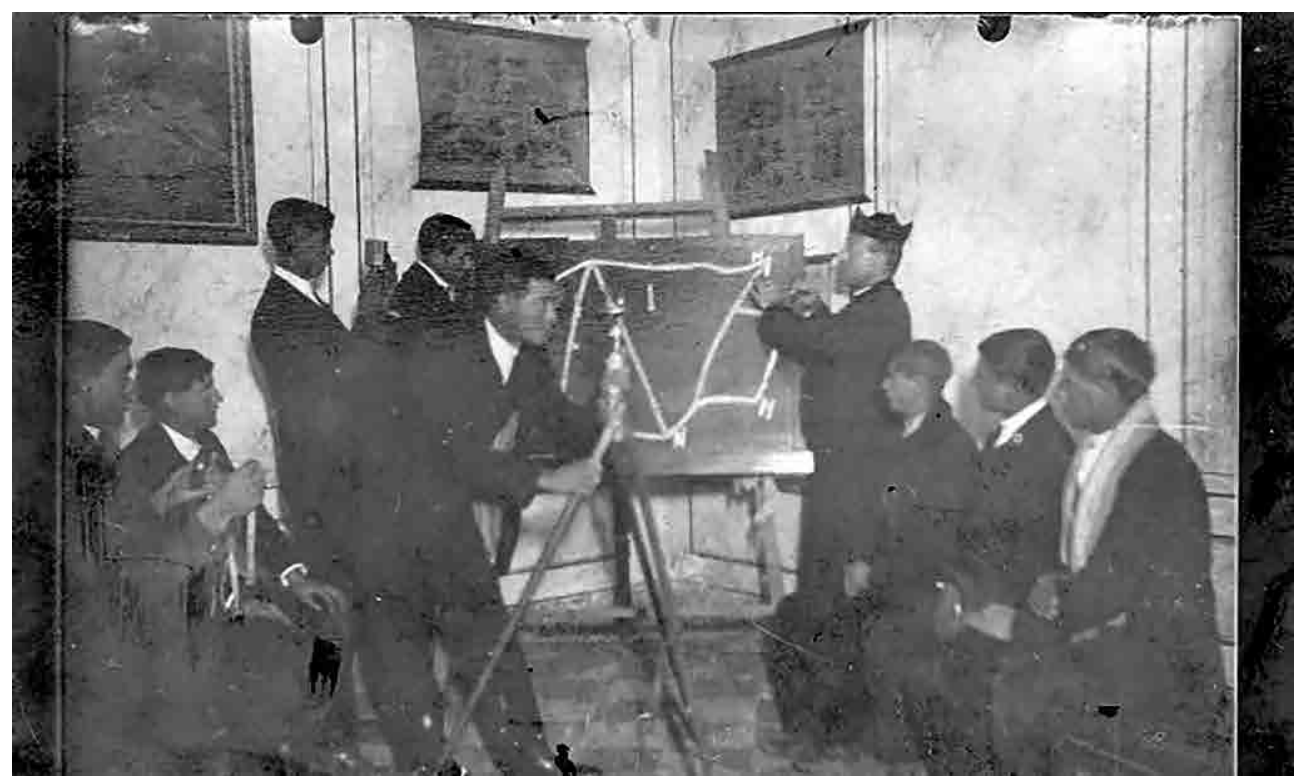

Tarjeta postal impresa con imágenes de la Escuela del Sagrado Corazón de Los Santos para enviar a familiares y amigos en 1915. Se escenifica una clase de Agricultura en la Escuela de Adultos impartida por Ezequiel Fernández Santana. Una imagen similar, en esta misma sala y con idénticos alumnos, se utilizó para la edición de Organización y procedimientos Pedagógicos de las Escuelas Parroquiales de Los Santos (1920). Imagen para imprenta, posible revista ilustrada 9 por 12 con filetes (Herederos de Ezequiel Fernández Santana. La Parra). 
Figura 2. Apéndice fotográfico 2. Restauración de placas fotográficas.

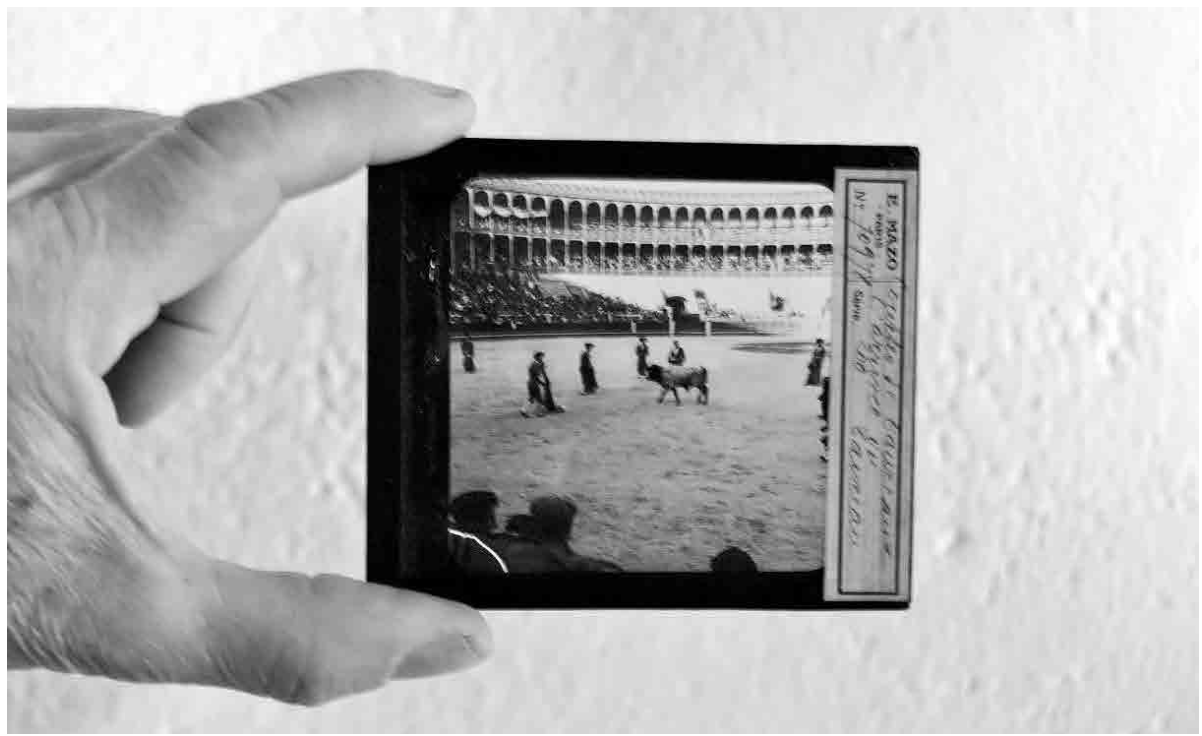

Fondo Familiar (Caja 2, 10 x 8'50 x 0’3).

“Courses de Taureaux / arrivée de L'Espada". No “70981”. Série “200”. (PROJECTIONS - MAZO- PARIS / Autorisation de Projeter).

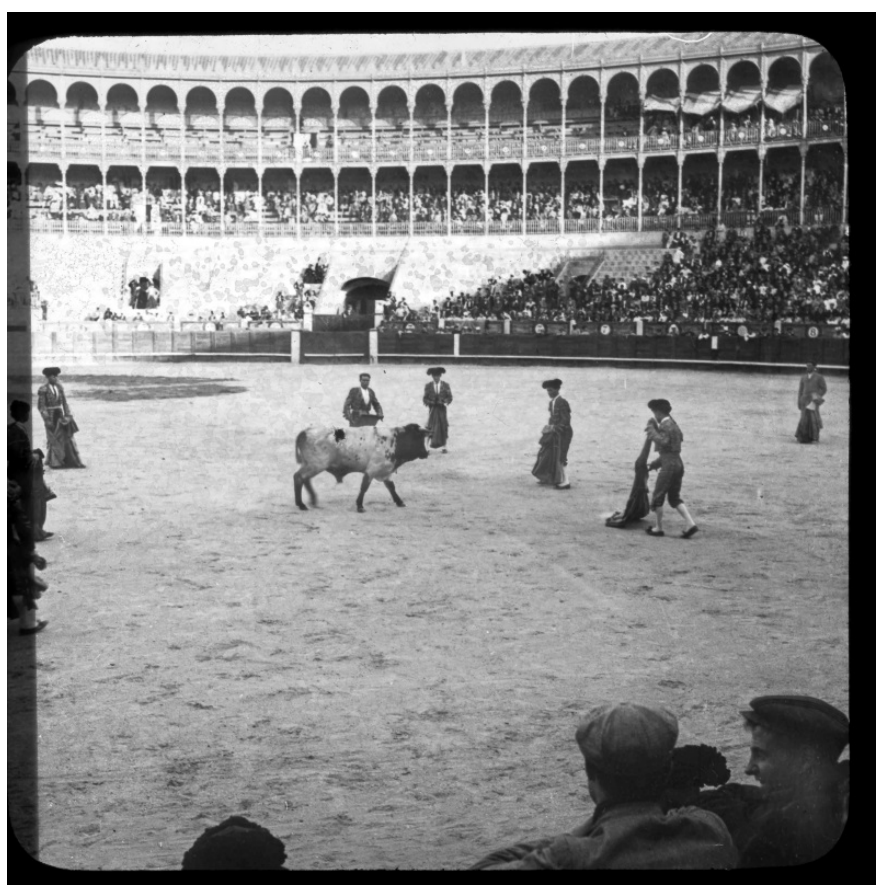

Fondo Familiar (Caja 2, 10 x 8’50 x 0’3). Ejemplo de restauración de la imagen, eliminando la rotura del cristal y limpieza de las partes ensombrecidas por la suciedad. 
Figura 3. Apéndice fotográfico 3. Base de datos de la producción fotográfica: ejemplo de entrada en la Fototeca digital.

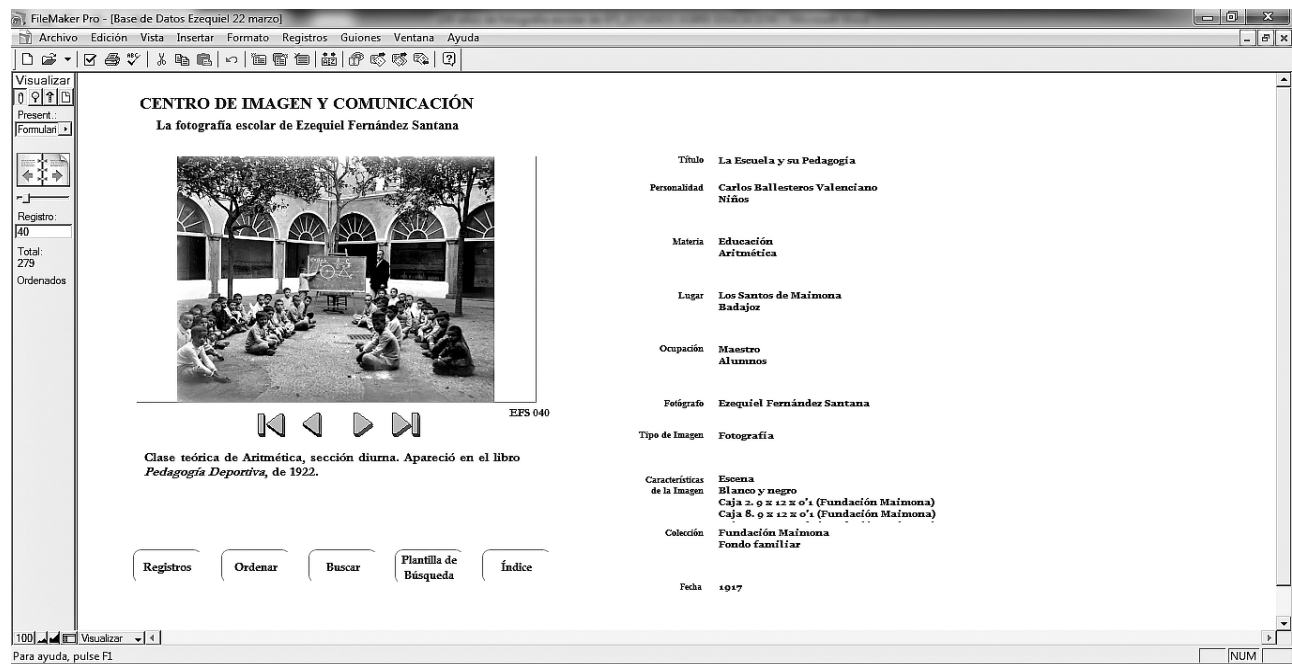

Modelo de la base de datos elaborada con todo el fondo fotográfico y los campos registrados en la documentación: breve explicación del contenido; título (atendiendo a su temática); personas que aparecen en la misma; materia; lugar donde se ubica la imagen; ocupación de los personajes registrados; fotógrafo; tipo de imagen; características físicas; fondo fotográfico y fecha.

Figura 4. Apéndice fotográfico 4. Ejemplos de tomas fotográficas parejas.
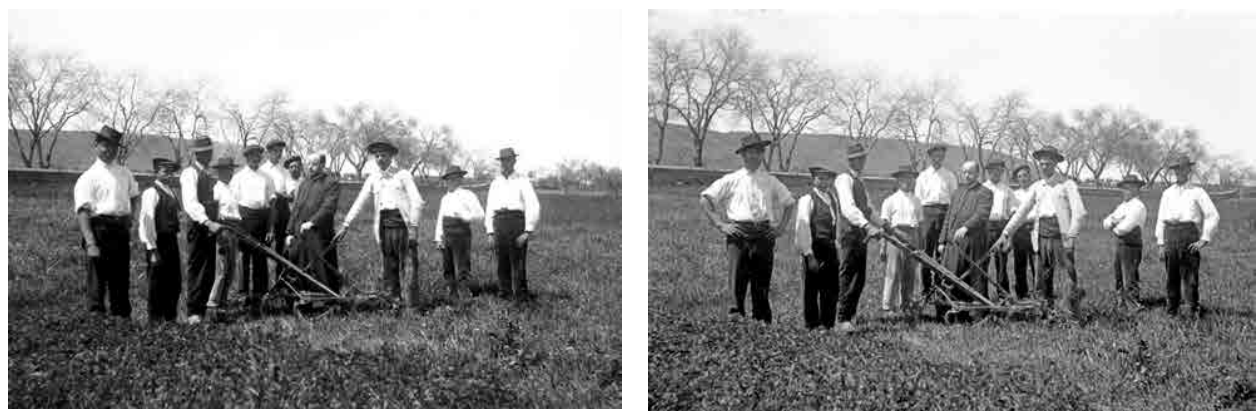

Fundación Maimona. Alumnos en el Fundación Maimona. Alumnos en el Campo de experimentación (1). Clases prácticas.

Campo de experimentación (2). Clases prácticas. 


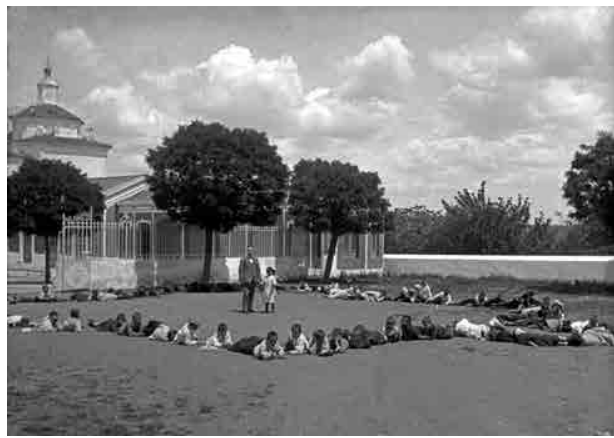

Fundación Maimona. Clase de Geografía en la ermita de Ntra. Sra. de la Estrella en 1917 (1). Clases prácticas.

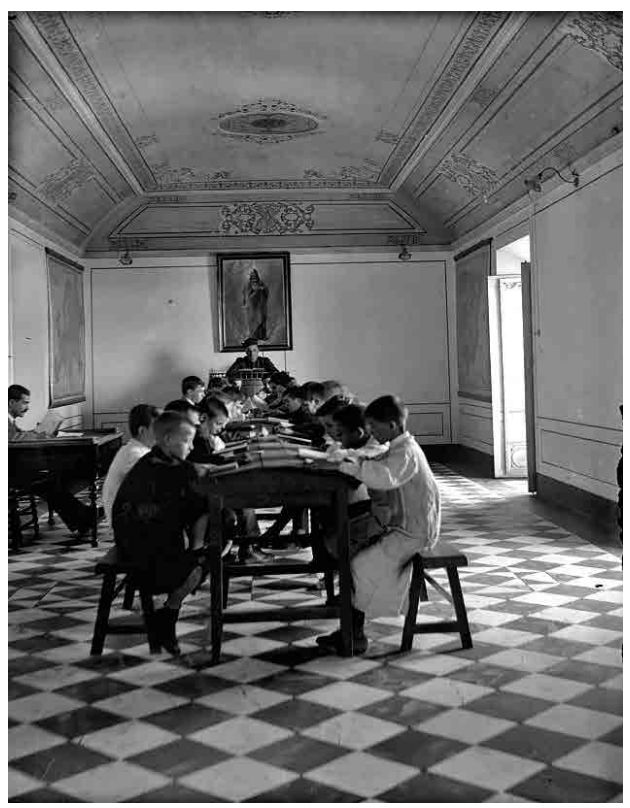

Fundación Maimona. Alumnos en la Sala de Estudios (1).

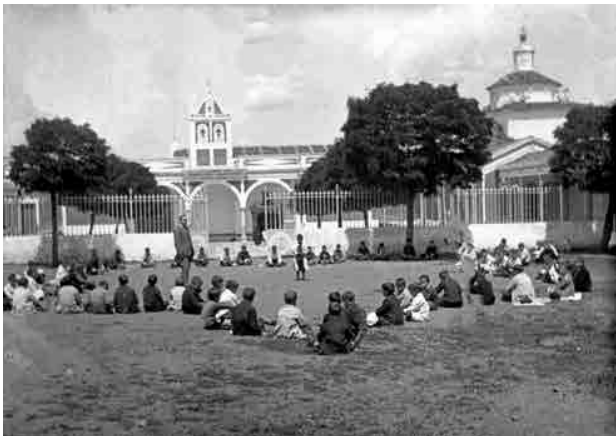

Fundación Maimona. Clase de Geografía en la ermita de Ntra. Sra. de la Estrella en 1917 (2). Clases prácticas.

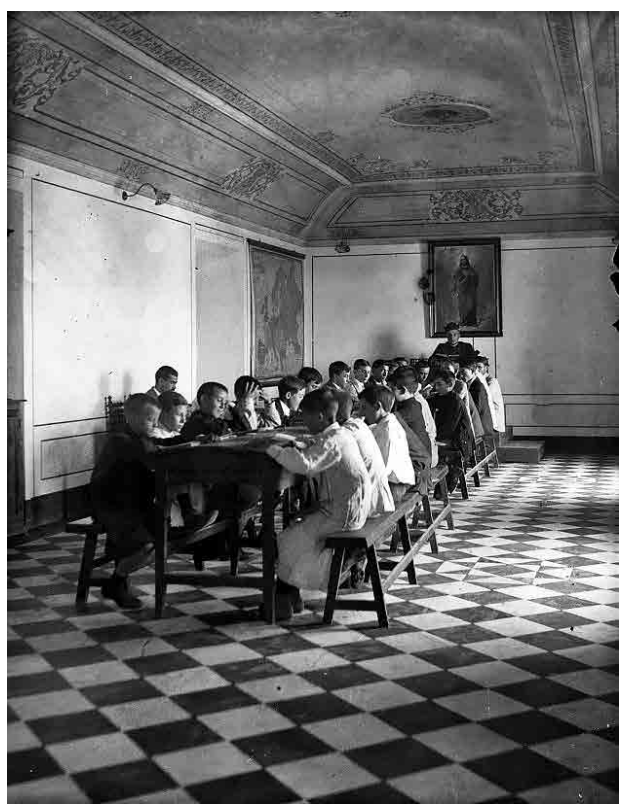

Fundación Maimona. Alumnos en la Sala de Estudios (2). Segunda Enseñanza, Organización y procedimientos Pedagógicos de las Escuelas Parroquiales de Los Santos (1920). 


\section{FUENTES}

Aguiló Ribas, C., M. J. Mulet Gutiérrez y P. Pinya Llinàs. “La fotografia de temàtica escolar en arxius no especialitzats. Notes sobre fons en imatge a Mallorca". Educació i Història: Revista d'Història de l'Educació, no. 15 (2010): 73-98.

Arata, N. "Imágenes de la escuela rural. Apuntes sobre las fotografías de Cecilia Gallardo". Propuesta Educativa 40, No. 2 (2013): 99-110.

Argerich, I. "Imatges fotogràfiques de temàtica educativa en colleccions i arxius públics i privats". Educació i Història: Revista d'Història de l'Educació, no. 15 (2010): 55-72.

Baeza, J. Por una función crítica de la fotografía de prensa. Barcelona: Gustavo Gili, 2001.

Comas, F. "Fotografía i història de l'educació". Revista d'Història de l'Educació, No. 15 (2010): 11-22.

Comas Rubí, F., X. Motilla Salas y B. Sureda García. “Iconografía y representación gráfica de las colonias escolares de la Diputación de Baleares. Una aproximación a través del análisis de las fotografías de las memorias". Revista Española de Pedagogía LXIX, No. 250 (2011): 445-462.

Díaz Barrado, M. P. “Una visión de España en el siglo XX: instantes fotográficos para construir la memoria". Berceo, no. 149 (2005): 87-108.

Díaz Barrado, M. P. y P. Martínez-Vasseur. La imagen de España y Francia en los medios de comunicación. Cáceres: Universidad de Extremadura, Servicio de Publicaciones, 2003.

Depaepe, M., B. Henkens (Eds.). Imagine, all the education... The visual in the making of the educational space through history. Programme and abstract book of the XXth International Standing Conference for the History of Education. Leuven: ISCHE, 1998.

Fischman, G. E. "Las fotos escolares como analizadores en la investigación educativa". Educaçao e realidade 31, no. 2 (2006): 79-94.

Fernández Santana, E. Boletín Parroquial. Los Santos de Maimona: Hermanos Sánchez, 1912-1915.

Fernández Santana, E. Conferencia pronunciada en la Semana Agrícola de Badajoz. Badajoz: Vicente Rodríguez, 1912.

Fernández Santana, E. Narraciones Apologéticas. Los Santos de Maimona: Hermanos Sánchez, 1916.

Fernández Santana, E. Las Cajas Rurales extremeñas. Los Santos de Maimona: Hermanos Sánchez, 1917.

Fernández Santana, E. ¿Escuelas o Sindicatos? Los Santos de Maimona: Hermanos Sánchez, 1917.

Fernández Santana, E. Nuestra Escuela. Los Santos de Maimona: Hermanos Sánchez, 1919.

Fernández Santana, E. Organización y Procedimientos Pedagógicos de las Escuelas Parroquiales de Los Santos. Madrid: Editorial Reus, 1920.

Fernández Santana, E. Pedagogía Deportiva. Badajoz: Joaquín Sánchez, 1922.

Fernández Santana, E. La Cuestión Social en Extremadura. Los Santos de Maimona: Imp. Boletín Parroquial, 1935.

Fernández Santana, E. Catecismo Social. Huelva: Muñoz Imprenta-papelería, S.R.C., 1947. Fernández Santana, E. La Cuestión Política en España a la Luz de las Encíclicas. Inédito. 
Fontanella, L. La historia de la Fotografía en España desde sus orígenes hasta 1900. Madrid: El Viso, 1981.

Fontanella, L. Clifford en España: un fotógrafo en la corte de Isabel II. Madrid: El Viso, 1999. Freund G. La fotografía como documento social. Barcelona: Gustavo Gili, 1976.

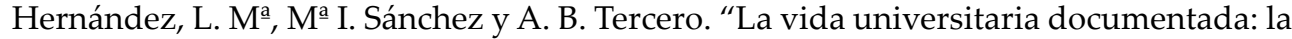
fototeca digital de la Universidad de Castilla-la Mancha (Ciudad Real, España)". En Actas de las XI Jornadas de Gestión de la Información. Madrid: SEDIC, 2009, 255265.

Ibáñez González, R., L. Monjón, J. Pedro, M. Sánchez Luque y R. M.Villalón Herrera. “El archivo fotográfico en la Unidad de Tratamiento Archivístico y Documentación (UTAD) del Centro de Ciencias Humanas y Sociales del CSIC". En XI Jornadas de Gestión de la Información: Servicios polivalentes, confluencia entre profesionales de archivo, biblioteca y documentación. Madrid: Sociedad Española de Documentación e Información Científica, 2009, 225-236.

Kurtz, G. e I. Ortega. 150 Años de Fotografía en la Biblioteca Nacional. Madrid: El Viso, 1989. López Mondéjar, P. Fuentes de la Memoria 1. Fotografía y Sociedad en la España del siglo XIX. Madrid: Ediciones Lunwerg, 1989.

López Mondéjar, P. Visiones del Deporte. Deporte y Fotografía en España, 1860-1939. Madrid: Ediciones Lunwerg, 1991.

Motilla Salas, X. "Imagen y proyección pública de las colonias escolares de la Menorca de principios del siglo XX. Una aproximación a través del análisis de la prensa y las fotografías". Foro de Educación, no. 13 (2011): 123-138.

Muro, M. "La fotografía en Extremadura. Tránsito del siglo XIX al XX". Revista de Estudios Extremeños 55, no. 1 (1999): 137-168.

Muro, M. "La fotografía en Extremadura". Atlántica. Revista de Arte y pensamiento, No. 27 (2000): 120-139.

Muro, M. Fotografía en Extremadura hasta 1951. Mérida: Editora Regional de Extremadura, 2009.

Newhall, B. The History of Photography from 1839 to the Present Day. New York: Museum of Modern Art, 1964.

Newhall, B. Historia de la fotografía. Madrid: Ed. Gustavo Gili, 2001.

Piernavieja del Pozo, M. "Francisco Amorós. El primer gimnasiarca español". Citius. Altius. Fortius II, Fascículo 3, reedición de 1959 (1986): 275-313.

Ramos Escobar, N. “Origen y prospectiva del proyecto Memoria Escolar Fotográfica del Sistema Educativo Estatal Regular en San Luis Potosí". Revista Mexicana de Historia de la Educación 1, No. I (2013): 163-170.

Rodríguez López, J. Historia del deporte. Barcelona: INDE, 2000.

Sanchidrián Blanco, C. "El uso de imágenes en la investigación históricoeducativa". Revista de Investigación Educativa 29, No. 2 (2011): 295-309.

Sánchez, J. M. “Centros de documentación fotográfica: Fototecas, Archivos y Colecciones en España". En Manual de Documentación Fotográfica, editado por F. del Valle. Madrid: Editorial Síntesis, 1999, 19-42.

Sánchez Pascua, F. La Obra Socio-Educativa de Ezequiel Fernández Santana. Badajoz: Universitas Editorial, 1994.

Sánchez Vigil, J. M. El documento fotográfico: Historia, usos, aplicaciones. Madrid: Ediciones Trea, 2006. 
Soto Vázquez, J. Ezequiel Fernández Santana y la Literatura de Acción Social Católica. Cáceres: Servicio de Publicaciones de la Universidad de Extremadura, 2008.

Soto Vázquez, J. Pedagogía Deportiva. Madrid: Cultiva Comunicación, 2011.

Soto Vázquez, J. y A. Pantoja Chaves. Catálogo de la exposición La fotografía escolar de Ezequiel Fernández Santana (1915-1938". Los Santos de Maimona: Fundación Maimona, 2011.

Soto Vázquez, J. y A. Samino León. La enseñanza pública en Los Santos de Maimona a través de sus documentos. Badajoz: Diputación de Badajoz, 2014.

Sougez, M. L. 150 años de Fotografía en la Biblioteca Nacional. Madrid: Ministerio de Cultura, Ediciones El Viso, 1989.

Sougez, M. L. Historia de la Fotografía. Madrid: Ediciones Cátedra, 1994.

Souza, R. F. de "Fotografias escolares: a leitura de imagens na história da escola primária". Educar, No. 18 (2001): 75-101.

Sureda García, B. y F. Comas Rubí. “La transición en los modelos de la pedagogía del ocio a finales del franquismo a través de fuentes fotográficas: las colonias de verano de Can Tàpera en Baleares". Revista Lusófona de Educação, No. 25 (2013): 159-176.

Valle, F. del "El análisis documental de la fotografía". En Manual de Documentación Fotográfica, editado por F. del Valle. Madrid: Editorial Síntesis, 1999, 113-133.

Viñao, A. "La historia material e inmaterial de la escuela: memoria, patrimonio y educación". Educação 35, No. 1 (2012): 7-17.

Soto Vázquez, José; Pérez Parejo, Ramón. “La producción fotográfica escolar de Ezequiel Fernández Santana 100 años después (1915-2015)". Revista Historia de la Educación Latinoamericana. Vol. 19 No. 29 (2017): 271-302. 